\title{
Numerical investigation of an extreme storm with the Canadian Regional Climate Model: the case study of windstorm VIVIAN, Switzerland, February 27, 1990
}

\begin{abstract}
The windstorm VIVIAN that severely affected Switzerland in February 1990 has been investigated using the Canadian Regional Climate Model (CRCM). This winter storm was characterised by a deep cyclone in the North Atlantic and by strong geopotential and baroclinic north-south gradients in the troposphere over Western Europe resulting in high windspeeds in Switzerland. Our principal emphasis is to demonstrate the ability of the CRCM to simulate the windfield intensity and patterns. In order to simulate winds at very high resolution we operate an optimal multiple self-nesting with the CRCM in order to increase the horizontal and vertical resolution. The simulation starts with downscaling NCEP-NCAR reanalyses at $60 \mathrm{~km}$ with 20 vertical levels, followed by an intermediate $5-\mathrm{km}$ simulation with 30 vertical levels nested in the former. The $5-\mathrm{km}$ output is in a final phase used for initial and lateral conditions for a $1-\mathrm{km}$ resolution simulation with 46 vertical levels. The multiple self-nesting in the horizontal is necessary to reach sufficient resolution to better capture the orographic forcing that modulates the atmospheric circulation at fine scales, whereas the vertical resolution enhancement helps to better simulate the boundary layer that modulates the windspeed along the surface and better represents the atmospheric circulation with a complex vertical structure (low-level jets, gravity waves and frontal features). It has also been found that the simulated temporal variability of the windfield and of most variables at the finer scales increases with the increasing nesting frequency. This indicates that as we
\end{abstract}

S. Goyette $(\bowtie) \cdot M$. Beniston · P. Jungo

Institute of Geography, University of Fribourg,

Pérolles, CH-1700, Switzerland

E-mail: stephane.goyette@unifr.ch

D. Caya $\cdot$ R. Laprise

Department of Earth and Atmospheric Sciences,

Université du Québec à Montréal, B.P. 8888,

Succ. Centre-ville Montreal, Québec, Canada H3C 3P8 progress towards finer scales in the horizontal, the vertical and the nesting frequency enhancement helps to simulate windspeed variability. However, the variability within the larger domain is limited by the archival frequency of reanalysis data that cannot resolve disturbances with time scale shorter than $12 \mathrm{~h}$. Results show that while the model simulates well the synoptic-scale flow at $60-\mathrm{km}$ resolution, cascade self-nesting is necessary to capture fine-scale features of the topography that modulate the flow that generate localised wind enhancement over Switzerland.

\section{Introduction}

Extreme weather events have significant impacts on the natural environment and on many socio-economic sectors (e.g. Beniston 1997). These events tend to have a greater influence than shifts in mean values, which are commonly used as the fundamental quantity for discussing climatic changes. It is therefore of interest to predict the potential shifts of extremes in an altered climate.

Severe storms are the basis for severe weather, and a dominant characteristic is their associated high winds. Wind extremes, for example, are of great concern because they may lead to considerable damage to forests and man-made infrastructure, and disrupt numerous socio-economic activities. Since this crucial problem is of particular importance at the regional and local scales, it is therefore of prime interest to assess how well regional climate models (RCMs) can reproduce documented events. This step is a prerequisite to study the potential changes of extremes in an altered global climate as projected for the twenty-first century.

The Intergovernmental Panel on Climate Change (IPCC 1996) has identified mountainous regions as one of the more sensitive environmental systems which require particular attention in terms of both fundamental climate processes and the impacts of climate change 
(Beniston et al. 1997). It is of interest to know the extent to which extreme wind event frequency over mountainous regions may be sensitive to global change. Most extreme cases are defined as "unusual" events and little is known about their genesis, intensities, duration, return periods and frequency distributions. Even though much is known concerning local wind climatology as well as other fundamental quantities, this is not the case for most extreme events.

Certain mountain regions such as the Alps are densely populated and play a key role in their economy and social sectors. Extreme wind events are likely to have major impacts on these sectors, notably on forests (Holenstein 1994; Combe 1998). Thus it appears reasonable to focus first on a particular region affected by extreme wind events which are well-documented in terms of meteorological records, to develop techniques to test and validate regional models, and to refine the diagnostic tools in order to gain deeper insights into the phenomenon. Case studies of severe windstorms over Western Europe with a numerical approach appear worthwhile to evaluate the model skill on the one hand, and to develop the tools which will be needed to build a "climatology" of future wind extremes in Switzerland, on the other hand.

The Swiss Alps are by far the best-documented mountain area in the world in terms of weather and climate and related environmental characteristics (Barry 1992). Several summit observatories have records spanning 100 years and a dense network of regular observing stations covers Switzerland. This region thus provides the best information to conduct and validate numerical experiments in highly complex orography.

Analyses of changes in the simulated climate extremes have been attempted on a global basis with general circulation models (e.g. Zwiers and Kharin 1998). However, a similar study over Switzerland requires a regional investigation using a RCM in many respects. First, most of the impacts from anticipated climatic change are associated with fine scale processes so that the use of a high-resolution model is essential; second, a fine modelgrid mesh is needed to resolve the complex terrain of the Alps; third, such a limited-area model is computationally very efficient compared to a global model of similar mesh size. Once a contemporary climate has been simulated and validated against observed climatology, a climate change experiment can be performed in order to evaluate the shifts in the simulated extremes. Regional climate models have proved to be successful over complex terrain of North America (Dickinson et al. 1989; Giorgi and Bates 1989), Europe (Giorgi et al. 1992; Jones et al. 1995), and over the Alps (Marinucci et al. 1995; Rotach et al. 1997) to characterise climatic variability at fine scales.

The Canadian Regional Climate Model (hereinafter referred to as CRCM) is one such model capable of simulating climate at high spatial resolution. CRCM was developed at the Université du Québec à Montréal jointly with the Canadian Centre for Climate modelling and analysis in Canada (Caya et al. 1995; Caya and Laprise 1999). The results of Laprise et al. (1998) highlight its potential for continuous multi-year simulations at $45-\mathrm{km}$ resolution over western Canada.

A "companion" version of the CRCM, with the same dynamics but different physical parameterization packages, nicknamed MC2, currently used at the meteorological services at MSC-RPN (Meteorological Service of Canada-Recherche en Prévision Numérique in Montréal) by Benoit et al. (1997) was run in a self-nesting mode in order to verify its capability to simulate a large range of atmospheric flow by simulating an Atlantic winter cyclogenesis over the east coast of North America and local downslope windstorm over modest topography. The self-nesting technique has also been used by Christensen et al. (1998) to scale down Scandinavian climate to $19-\mathrm{km}$ resolution. Although there are clear indications that the higher resolution helped to solve a number of regional details of the climate, the model performance is limited by the quality of the large-scale driving data and by limitations in certain physical parametrisation schemes.

During the months of January and February 1990, a series of deep cyclones intensifying over Scandinavia induced widespread extensive wind damage in Western Europe. Widespread and damaging gales affected the United Kingdom (McCallum and Norris 1990; Hammond 1990) and Switzerland (Schüepp et al. 1994). These windstorms together caused more than 10 billion US $\$$ in damage. More than 50 million cubic meters of harvestable timber was destroyed in Germany, Austria, Czechoslovakia, Switzerland, and France (Flavin 1994). These exceptional events produced extreme wind speeds measured at a number of alpine pass stations. In order to evaluate the CRCM's ability to reproduce such an extreme wind event, we simulated a particular windstorm known as VIVIAN that affected Switzerland in late February 1990 and compared results with observed data.

The spatial and temporal resolution of contemporary reanalysis data is still too coarse to diagnose regional wind patterns, their strength, and their evolution over complex topography characteristics of Switzerland. We assume that the synoptic-scale patterns found in reanalysis data are sampled accurately enough to be used as input in RCMs in order to simulate atmospheric circulation at higher resolution within the complex orography of Switzerland.

This study describes the methodology used to simulate the windstorm VIVIAN with the help of the CRCM and provides an overview of the model's performance. Section 2.1 gives a description of the CRCM and the approach to down track extreme wind events over Switzerland on the basis of the National Centers for Environmental Prediction-National Center for Atmospheric Research $(N C E P-N C A R)$ reanalysis data. Then we describe in Sect. 2.2 the multiple nesting technique used to downscale the atmospheric circulation to $1 \mathrm{~km}$. We furthermore compare model results with station observations. We finally discuss the overall model's 
performance in Sect. 4 and conclude this study in Sect. 5 .

\section{Description of CRCM}

The Canadian regional climate model (CRCM) is outlined in Caya et al. (1995), a full description and a short-term simulation is presented in Caya and Laprise (1999), and long-term simulations are described in Laprise et al. (1998). The numerical formulation is based on a semi-Lagrangian semi-implicit nonhydrostatic dynamical kernel (Laprise et al. 1997), and on the physical parametrisations of the second-generation Canadian General Circulation Model (GCMII; McFarlane et al. 1992). The CRCM numerical formulation solves the fully elastic Euler equations to compute the evolution of the atmospheric flow. CRCM atmospheric variables are discretized on an Arakawa C-type staggered grid on a polarstereographic projection in the horizontal and Gal-Chen terrainfollowing scaled height co-ordinates in the vertical. The model physics includes the unresolved turbulent and convective transfer processes, radiation, cloud formation, the generation of precipitation and latent heat release, as well as surface energy balance and hydrology.

CRCM being a limited-area model (LAM), it is necessary to prescribe its boundary conditions. The lateral and uppermost nesting consists of driving the CRCM with a time series of observed or model-generated atmospheric fields, namely pressure, temperature, water vapour and horizontal wind components, at the external boundaries. An external sponge frame of variable width may damp these driving conditions where they are gradually blended with corresponding simulated fields in the interior. The overall nesting procedure used here is designed to be oneway, i.e. CRCM does not feed-back into the driving data. In addition, the CRCM has an option allowing to nudge the largescale flow over the whole domain. This technique called "spectral nudging" (Biner et al. 2000), thus prescribes the evolution of larger scales of the circulation and allows the model to develop its short flow pattern, scales. This permits us to use domains of any size where the simulated synoptic patterns correspond to the observed ones.

At the surface a set of geophysical and other land/ocean fields are prescribed onto CRCM surface grid (SSTs, orography height, soil and vegetation characteristics, for example). In this work, the orography height of the Alps is of prime importance because its complexity determines lower level circulations that affect the values of wind velocity.

Output data from a previously made run of the CRCM may be used to drive an ensuing run at higher resolution. This multiple selfnesting technique is used for a cascade downscaling. In our case, $N C E P-N C A R$ reanalysis are first downscaled to $60 \mathrm{~km}$ as a first step, then the CRCM $60-\mathrm{km}$ atmospheric outputs serve as driving nesting conditions for subsequent simulations with the same model. This ensures a smoother transition towards the finer scales, thus allowing the atmospheric structures to be simulated with more realism given the complexity of the orography.

The wind variable used for comparison with observations is the simulated anemometer-level wind. In the CRCM, the first prognostic level for momentum is several tens of metres above the resolved surface so that the lowest level windspeed may not be typical of the winds at the anemometer level. The CRCM physics includes a diagnostic computation of the anemometer-level $(10 \mathrm{~m})$ windspeed according to similarity theory. The simulated anemometerlevel wind is computed using the first momentum-level windspeed modulated by frictional and stability effects. This wind is computed every time step and then averaged over the archival period, here fixed at $1 \mathrm{~h}$. The hourly maximum, which is taken as the strongest windspeed during the hour cannot be compared directly with the observed maximum, the latter being essentially the result of a gust while the former is not. In the current version of the CRCM, there is no provision to compute gusts as such that need to be resolved explicitly by higher order equations.

\subsection{Experimental setup}

The model configuration, the nesting, the initialisation aspects and the length of the integrations have been devised to progress rapidly towards higher resolution, and to show that a reasonably successful simulation of windstorms can be achieved with the CRCM. It should be noted that these steps should not be understood as a general rule for all windstorm cases to be downscaled, but only be valid in the present context so as to shorten the nesting procedure. Sensitivity studies involving various horizontal and vertical model resolutions, as well as archival frequency, indicated that a "reasonable" cascade self-nesting configuration to simulate intense surface winds of windstorm VIVIAN consists of downscaling $N C E P-N C A R$ reanalysis at $60 \mathrm{~km}$ with CRCM having 20 vertical levels, and an archival period of $6 \mathrm{~h}$. This then is used to nest the simulation at $5 \mathrm{~km}$ with 30 vertical levels, and an archival period of $1 \mathrm{~h}$, the latter finally serving to nest the simulation at $1 \mathrm{~km}$ with 46 vertical levels.

Our choice is motivated consequently. It has been suggested that the ratio of grid meshes during a cascade self-nesting procedure should be taken between 3 and 6 ; this implies that to reach $1 \mathrm{~km}$ from the initial downscaling of large scale data at $60-\mathrm{km}$ resolution, at least two intermediate simulations should be performed. Despite this empirical "rule", the Canadian MC2, a version of a LAM close to the Canadian CRCM, has been found to be rather insensitive to this factor (Benoit et al. 1997). In our study even larger factors have been tested and, interestingly enough, the CRCM was not found to be sensitive to the embedding of an extra simulation at $20 \mathrm{~km}$ "linking" the $60-$ and the $5-\mathrm{km}$ resolution ones. It has been noticed that the use of an extra $20-\mathrm{km}$ resolution simulation does lengthen the experimental setup but, on the other hand, it cannot be concluded that any new significantly different results are simulated on finer scales. To illustrate the influence of the use of this additional $20-\mathrm{km}$ simulation on the subsequent nested 5-km simulation, domain average RMS of temperature, windspeed, and specific humidity differences between the $5-\mathrm{km}$ simulation driven at its lateral boundary respectively by the $60-\mathrm{km}$ simulation and by the $20-\mathrm{km}$ simulation is computed. This quantity is defined as:

$R M S=\left(\frac{\sum_{i}\left(\psi_{i}^{(60-20-5)}-\psi_{i}^{(60-5)}\right)^{2}}{N_{b}}\right)^{1 / 2}$

where $N_{b}$ is the total number of model grid points summed over the $i$ th, $\psi^{(60-20-5)}$ is the value of a variable simulated at $5 \mathrm{~km}$ resolution during the cascade self-nesting at 60 - and $20-\mathrm{km}$, whereas $\psi^{(60-5)}$ is the value of the variable simulated at $5 \mathrm{~km}$ resolution during the self-nesting at $60-\mathrm{km}$. This quantity may be considered as a measure of the discrepancies that exist between different simulations where higher RMS values imply higher discrepancies and vice versa. The discrepancies are indications of the degree of the convergence of the model's results. If there is convergence between model's results at $5-\mathrm{km}$ resolution, either $\psi^{(60-20-5)}$ or $\psi^{(60-5)}$ may be used to drive the subsequent simulation; otherwise, if the model's results diverge, the use of the latter may not be used to drive the $1-\mathrm{km}$ simulation with a good degree of confidence. Figure 1 shows how such RMSs evolve through time when averaged over the model domain excluding the 9-gridpoint buffer zone. It is noticed that for temperature, specific humidity and windspeed, the amplitude of the RMS values are greater at the beginning, then diminish with time and becoming small towards the end of the simulated period. Also, there is a general negative tendency at all levels in the lower troposphere so that the RMS values are greater in the beginning and smaller at the end of this period. In other words, RMS values are converging to small values with time for this specific event. Figure 2 shows simulated differences of the specific humidity plotted onto the CRCM 5-km grid. This field is one of the most difficult quantities to adjust under lateral boundary forcing. In addition, discrepancies occurring at the fine scale do generate big RMS differences. The largest discrepancies frequently occur in the buffer zone (not shown) and less often in the domain's interior. For example, the largest differences are due to the position 
Fig. 1 Domain average RMS of a temperature $(\mathrm{K})$, b specific humidity $\left(\mathrm{g} \mathrm{kg}^{-1}\right)$, and $\mathbf{c}$ windspeed $\left(\mathrm{m} \mathrm{s}^{-1}\right)$ differences between two simulations at $5-\mathrm{km}$ resolution with CRCM; the first one is driven with lateral boundary forcing from the $60-\mathrm{km}$ simulation, and the other is driven with lateral boundary forcing from an extra $20-\mathrm{km}$ simulation. The curves represent four different levels $(\mathrm{hPa})$ over a five-day period from February 24-28, 1990. The horizontal axis is the time elapsed in $\mathrm{h}$
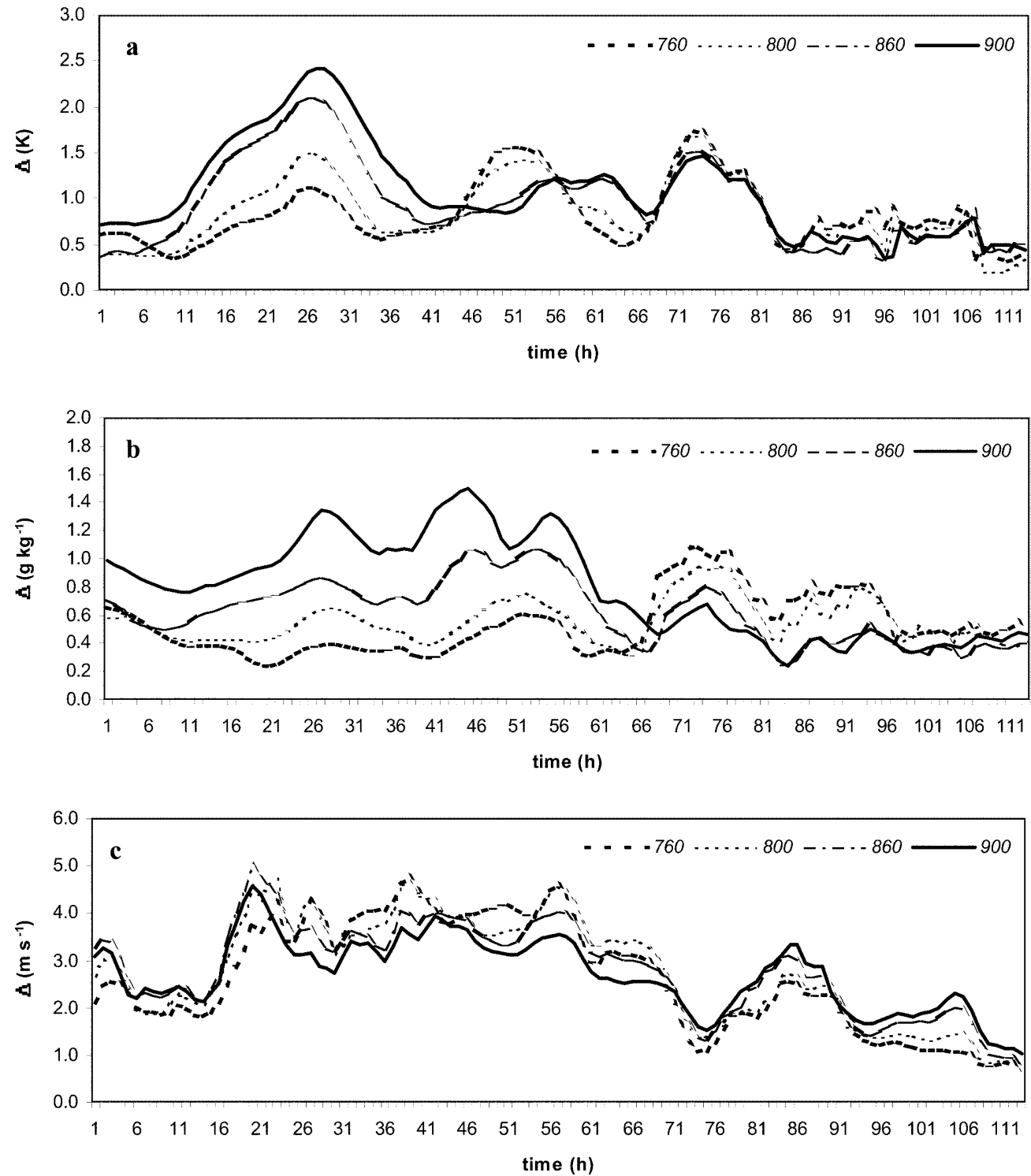

of the front of precipitation described in Sect. (3.1.2) that is still reproduced but differs slightly in position. At this point, is difficult to asses which one is better positioned when compared to observations (Schüepp et al. 1994; Fig. 5). This means that to a certain extent the model tends to constrain its atmospheric circulation so that the flow fields keep a certain consistency whenever the lateral boundary conditions that drive the model are "similar". It is also noticed in Fig. 2 that differences in the area of the model's interior that will provide the lateral boundary conditions for winds to the subsequent $1-\mathrm{km}$ resolution simulation are small. Accordingly, it was decided to drive the $5-\mathrm{km}$ simulation directly with the archived outputs of the $60-\mathrm{km}$ CRCM simulation.

On the other hand, the $1-\mathrm{km}$ simulation driven by the $60-\mathrm{km}$ one alone could not be made realistically without the transitional 5$\mathrm{km}$ simulation. In that case (not shown), the strong synoptic forcing provided periodically at the lateral boundaries from the 60 $\mathrm{km}$ simulation take over and dominate the atmospheric circulation from the top down to few levels above the model's surface. The model run at $1-\mathrm{km}$ resolution could simply not overcome this strong atmospheric forcing coupled to the considerable increase in spatial resolution. To support the choice of our nesting methodology, i.e., $60-5-1 \mathrm{~km}$, it can be understood that, from the surface point of view, the jump in spatial variability of the topography height is greater from the $5-\mathrm{km}$ resolution domain to the $1-\mathrm{km}$ domain than from the $60-\mathrm{km}$ domain to the $5-\mathrm{km}$ one. The spatial variability of the orography at the fine scales is to some extent generated by the Jura mountains and much by Alpine regions. Consequently, in order to capture the spatial and temporal variability of the atmospheric circulation from the surface and also higher above over the southern Alps, the 1-km resolution simulation has to be driven by lateral and surface conditions coming from those which would prevail in a situation closer to it, i.e., namely those at $5-\mathrm{km}$ resolution.

Now considering the length of the simulations, Caya and Biner (2000) have addressed the problem of the sensitivity to the initial and lateral boundary forcing with the CRCM. They have shown that distinct LAM simulations produced with the CRCM are developing almost the same high-resolution structures with time when they share the same set of low-resolution lateral boundary conditions. At $45-\mathrm{km}$ resolution, the time taken for a noticeable decrease of the domain averaged RMS differences between simulations starting each one at different time ( days) and the control simulation, is in the order of a week. In addition, there are some indications that at finer resolution the model adjusts even more rapidly. The adjustment under large-scale lateral boundary forcing to finer scales can thus be assessed through a relaxation time period. This can also be illustrated with RMS differences (Eq. 1) of atmospheric fields simulated with the CRCM at $5-\mathrm{km}$ resolution initialised at 


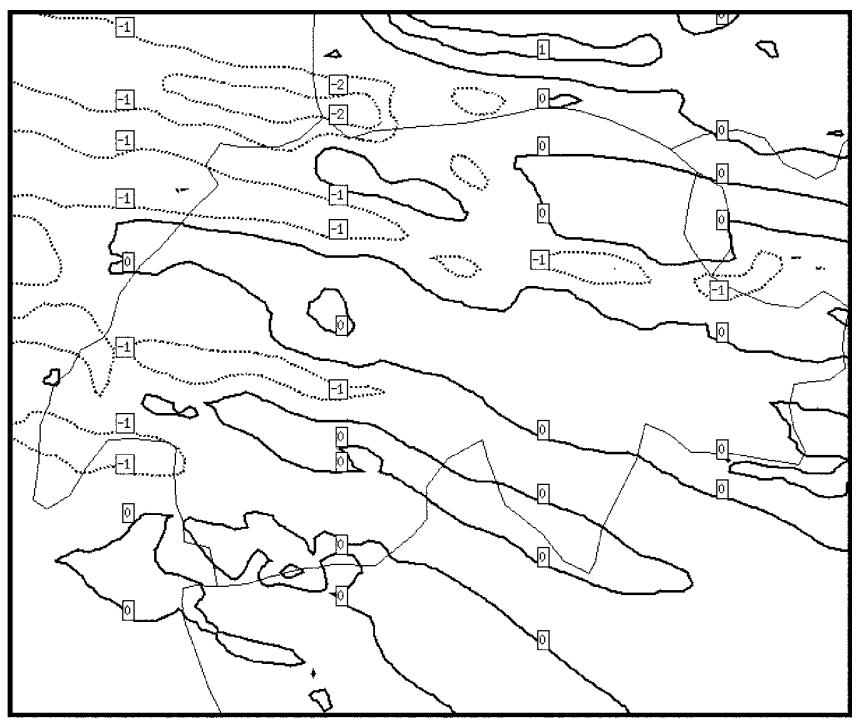

Fig. 2 Atmospheric specific humidity differences $\left(\mathrm{g} \mathrm{kg}^{-1}\right)$ at $700 \mathrm{hPa}$, at 1200 UTC on February 27, 1990, between two CRCM simulations at $5-\mathrm{km}$ resolution, the first one is driven at its lateral boundaries by outputs of the $60-\mathrm{km}$ simulation, and the other by outputs of the $20-\mathrm{km}$ simulation. Contour interval is $1 \mathrm{~g} \mathrm{~kg}^{-1}$

different starting times. Figure 3 shows how such differences evolve with time, averaged over the model domain excluding the 9-gridpoint buffer zone, with two CRCM simulations, one started two days prior to the other. In this example, the RMS differences are significant at the initial time up to few hours due to the different initial conditions. The same behaviour is found on many levels in the lower troposphere; the lowest levels show larger differences on the average. At later times, the domain-averaged RMS difference is decreasing as the fine-scale structures develop and stabilise around small values after about $12 \mathrm{~h}$. The time at which the RMS differences are becoming small is in the order of a day for specific humidity, and even shorter than that for temperature and for windspeed. Field differences of the specific humidity, temperature and windfield plotted onto the CRCM $5-\mathrm{km}$ grid are small throughout the period (not shown). Consequently, a one-day spinup for the atmosphere is found to be acceptable in the 5-km RCM since after this relaxation time the differences in the two simulations are not significant. At $1-\mathrm{km}$ resolution, domain-averaged RMS differences of atmospheric fields simulated with the CRCM are also becoming small after few hours (not shown). However, for practical reasons and due to computing and memory loads, we could not afford to make it longer than two days.

The cascade self-nesting downscaling technique involves the use of several subdomains as shown in Fig. 4. The downscaling of $N C E P-N C A R$ data is carried out on domain $A$. The intermediate nesting on domain $B$ provides a better spatial scale transition, since it allows the atmospheric circulation to adapt to the complex terrain. Over the domain $C$, the model is run at high resolution with a very realistic topographic representation of the Alps. Domain $C$ enables simulated winds to be compared locally with observed winds. It is noticed in Fig. 1 as we progress from domain $A$ to $C$, that the topographical features of the Alps are better resolved. In domain $A$, although the outline of the Alps is somewhat captured, none of the alpine complexity is resolved; for example the highest peak merely reaches $1380 \mathrm{~m}$. In domain $B$, some details begin to emerge. The Jura Mountains in northwest Switzerland and the Alps begin to appear as independent features, where the highest peaks reach $2900 \mathrm{~m}$. In domain $C$, numerous details are now accurately captured, the Rhône Valley is resolved as well as many of its tributary valleys; the northern alpine summits peak at $3400 \mathrm{~m}$ in the Jungfrau massif, and the Dom massif peaks at $3570 \mathrm{~m}$ to the south.

\subsubsection{The 60-, 5- and 1-km simulations}

Details about the setup of the simulations are listed in Table 1; momentum levels are depicted in Table 2. The spectral nudging technique used for the synoptic-scale circulation of NCEP-NCAR reanalysis data with the $60-\mathrm{km} C R C M$ is described in Biner et al. (2000). The NCEP-NCAR data (Kalnay et al. 1996) available to us, provided by the Canadian Centre for Climate modelling and analysis (CCCma), is $2.5^{\circ}$ resolution filtered to spectral T32/L12 extending from mean sea-level to approximately $50 \mathrm{hPa}$ aloft, with an archival period of $12 \mathrm{~h}$. The driving conditions of temperature, humidity, pressure, and winds are provided to the CRCM at $60-\mathrm{km}$ resolution every $12 \mathrm{~h}$ covering the period of integration. The landsea mask and the height of the orography are, as for many other geophysical surface properties (land-cover, soil characteristics, etc.), taken from a $1^{\circ} \times 1^{\circ}$ reference file. The SSTs and sea-ice coverage are taken from the $1^{\circ} \times 1^{\circ}$ resolution dataset of GISST (Rayner et al. 1996).

The domain used for the downscaling of the $60-\mathrm{km}$ simulation to $5-\mathrm{km}$ is centred over Switzerland. Because this experiment, as well as the following one at $1-\mathrm{km}$ resolution, is a resource-intensive high-resolution computation, it was necessary to run it on a reduced-size domain and for a shorter time period compared to the $60-\mathrm{km}$ simulation. The spectral nudging technique is not used in this experiment; the synoptic circulation above roughly $500 \mathrm{hPa}$ remains close to the one simulated at $60-\mathrm{km}$, however. The surface height resolved at $5 \mathrm{~km}$ is provided by Institut de Géophysique, Universite de Lausanne, Switzerland. The other geophysical surface properties are taken from the $1^{\circ} \times 1^{\circ}$ reference file. The driving conditions of temperature, humidity, pressure, and winds are provided by CRCM output data simulated at $60 \mathrm{~km}$. In order to reduce the spinup time of adjustment of the surface fields to the changed terrain, we initialised the ground temperature, its water content and the snow at the surface with end-of-period conditions previously simulated with the CRCM using the same model configuration. We believe this provides improved initial conditions at the surface.

The domain used for the simulation downscaling to $1-\mathrm{km}$ is centred over the Rhône valley in southern Switzerland. The topography, provided by Institut de Géophysique, Université de Lausanne is resolved at $1 \mathrm{~km}$ and smoothed spatially; this is done in order to avoid numerical problems in the flow fields that may result from too steep gradients. For this run, gravity wave drag and convective adjustment parametrisation schemes are turned off. The driving conditions of temperature, humidity, pressure, and winds are provided by CRCM output data simulated at $5 \mathrm{~km}$. Again, the surface temperature, water content and snow mass were initialised with end-of-period conditions previously simulated with the CRCM using the same model configuration.

\subsection{Overview of windstorm VIVIAN}

We provide here a succinct overview of the windstorm VIVIAN to facilitate the subsequent comparison with the simulated storm subsequently. A more thorough analysis is provided in Schüepp et al. (1994) on the basis of synoptic scale maps of the $D W D$ (German Weather Service; Deutscher Wetter Dienst) as well as on a combination of other regional data from many sources. Additional information on the winds that affected the United Kingdom and much of northern Europe can also be found in McCallum and Norris (1990) as well as in the weather bulletin of the Swiss Meteorological Institute (issued by Wetterbericht der Schweizerischen Meteorologischen Anstalt, SMA, Zürich).

During February 1990, the North Atlantic Ocean and Western Europe were under the influence of intense westerlies and winds were strong over Switzerland. On February 25 a deep 968-hPa low pressure centre travelled from southern Iceland and reached the Norwegian Sea on February 26. It deepened further to $948 \mathrm{hPa}$ and arrived in the Baltic Sea at 1200 UTC 27, February, continued its journey to the north of Scandinavia to the Barents Sea on March 1 at $952 \mathrm{hPa}$ and gradually occluded and filled. This cyclone that formed few days prior to February 25, 1990 off the coast of Newfoundland and its associated frontal system is known as 
Fig. 3 Domain average of RMS a temperature $(\mathrm{K})$, b specific humidity $\left(\mathrm{g} \mathrm{kg}^{-1}\right)$, and $\mathbf{c}$ windspeed $\left(\mathrm{m} \mathrm{s}^{-1}\right)$ differences between two CRCM simulations at $5-\mathrm{km}$ resolution, the first one started two days prior to the other. The curves represent four different levels $(\mathrm{hPa})$ over a three-day period from February 26-28, 1990. The horizontal axis is the time elapsed in $\mathrm{h}$
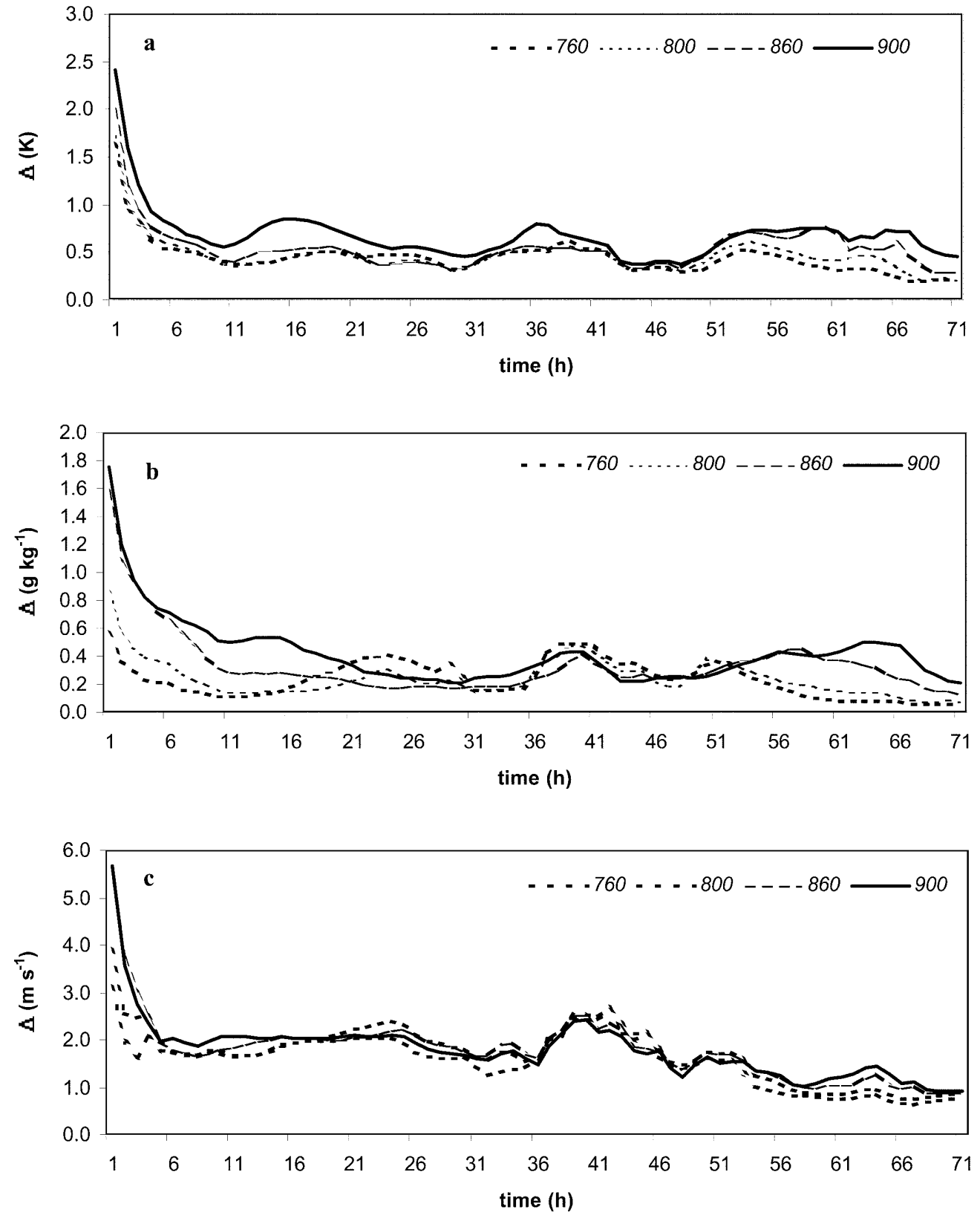

VIVIAN. This is a remarkable example of explosive cyclogenesis with a maximum deepening rate of $27 \mathrm{hPa}$ occurring between 0000 UTC and 1200 UTC on February 26 in the trough extending from the Norwegian Sea to the North Sea. This synoptic pattern over Europe was typical of an end-of-winter northwesterly situation but with higher pressure gradients oriented northeast to southwest over Western Europe. The strongest $1000 \mathrm{hPa}$ winds were found off the coast of Ireland in the Atlantic at more than $25 \mathrm{~m} \mathrm{~s}^{-1}$, and about $15 \mathrm{~m} \mathrm{~s}^{-1}$ over Switzerland. The strongest winds in the core of the jet-stream at $93 \mathrm{~m} \mathrm{~s}^{-1}$ were localised off the coast of Great Britain at $300 \mathrm{hPa}$ and oriented in a southeasterly direction towards France. As explained in Schüepp et al. (1994), the frontal zone moved from latitude $55^{\circ}$ to $50^{\circ} \mathrm{N}$ in the Atlantic between February 26 and 27 and reached Central Europe. Winds turned from W to WNW so that the first cold front reached Switzerland in the evening of February 26. Embedded in the powerful westerly jet within the elongated west-east front region a short baroclinic wave formed in the North Atlantic, deepened west of France to become a sec- ondary depression imbedded in the large Scandinavian low VIVIAN and moved east over Central Europe.

To illustrate concisely what happened during this intense episode, windspeed and temperature compiled by the $S M A$, data recorded from automatic weather stations (ANETZ) at the highaltitude Jungfraujoch station in the Alps are shown in Fig. 5. Observations, plotted from January 25 to March 3 1990, show that winds became especially strong around February 26-27: hourly mean windspeed reached $30 \mathrm{~m} \mathrm{~s}^{-1}$ (corresponding to 11 on the Beaufort scale, which denotes a violent storm), and maximum hourly wind gusts reached more than $60 \mathrm{~m} \mathrm{~s}^{-1}$. This maximum even reached more than $75 \mathrm{~m} \mathrm{~s}^{-1}$ at the Grand St. Bernard pass station at the Italian-Swiss border. For other stations at lower elevations, windspeeds were less intense, but in the range of other observed extreme values (Schüepp et al. 1994). On the lower curve, we can identify three cold fronts according to the sudden drop in temperature: the first reached the Jungfraujoch in the late afternoon of February 26, where temperatures dropped from $-6{ }^{\circ} \mathrm{C}$ to 
Fig. 4 Domains of integration. downscale NCEP-NCAR reanalyses at $60 \mathrm{~km}$. Intermediate domain $\mathbf{b}$ is used for the $5-\mathrm{km}$ simulation, and inner domain c is used for $1-\mathrm{km}$ simulation. Surface height topography $(\mathrm{m})$ is in grey scale The outer domain a is used to

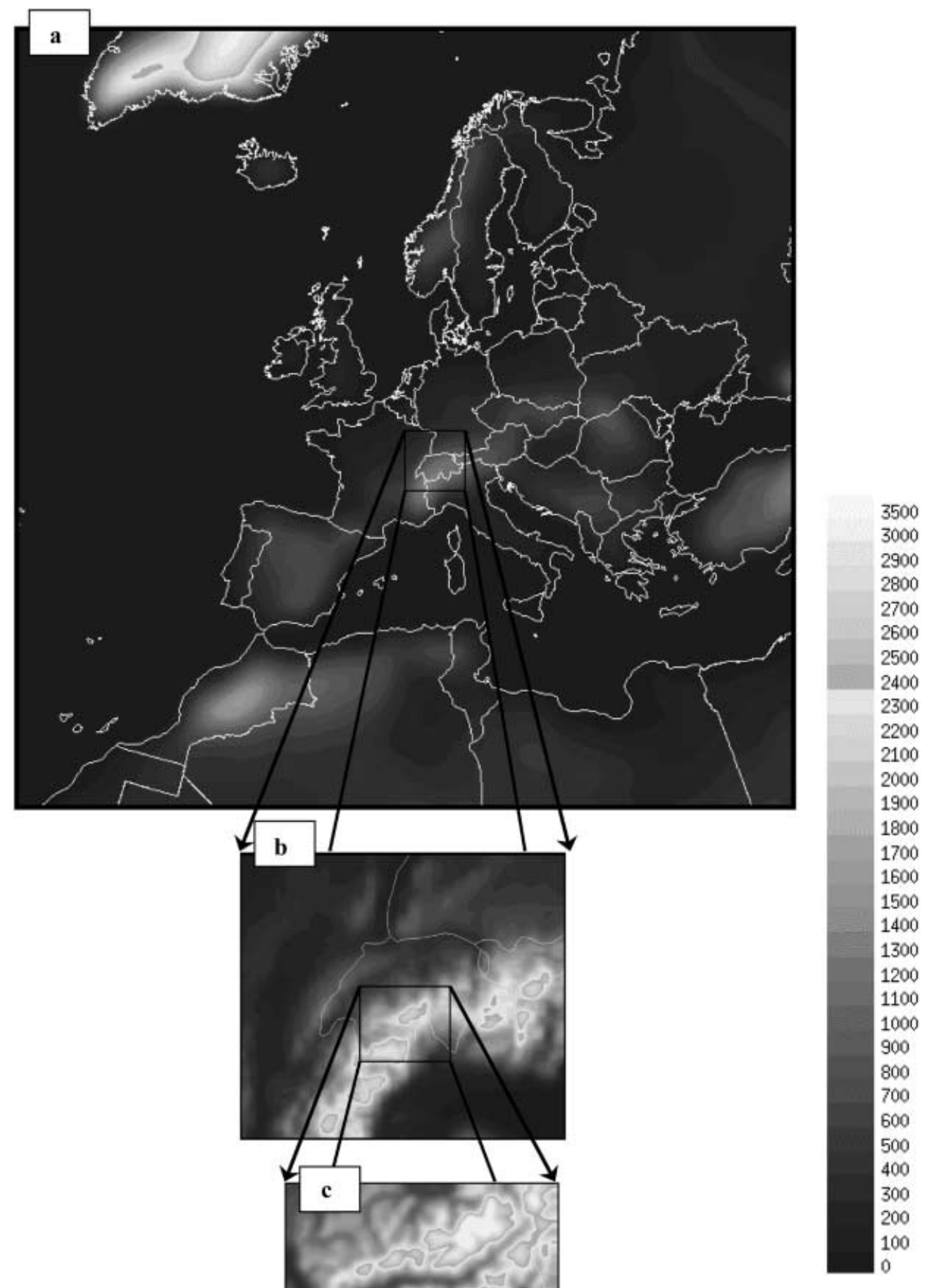

$-12{ }^{\circ} \mathrm{C}$, the second one in the afternoon of February 27 where temperatures dropped from $-10{ }^{\circ} \mathrm{C}$ to $-19{ }^{\circ} \mathrm{C}$, and the third one in the early morning of March 1 . Here temperatures dropped again from $-10{ }^{\circ} \mathrm{C}$ to $-19{ }^{\circ} \mathrm{C}$ but the associated front was responsible for minor damage compared with the first two. This storm mainly affected the alpine valleys of Switzerland where approximately 5 million $\mathrm{m}^{3}$ of timber were felled by the severe winds (Schüepp et al. 1994), in total affecting an area of about $50 \mathrm{~km}^{2}$. Most damage occurred on NW facing slopes whose inclination ranged from 50 to
$80 \%$, most of the slopes are located between 1200 and 1600 metres above mean sea level.

\section{Results}

In this section, the synoptic-scale circulation is discussed in terms of model results obtained at $60-\mathrm{km}$ resolution 
Table 1 Some details about the simulations

\begin{tabular}{|c|c|c|c|}
\hline \multirow[t]{2}{*}{ Characteristics } & \multicolumn{3}{|l|}{ Resolution } \\
\hline & $60 \mathrm{~km}$ & $5 \mathrm{~km}$ & $1 \mathrm{~km}$ \\
\hline Domain (Fig. 4) & A & B & $\mathrm{C}$ \\
\hline $\begin{array}{l}\text { Period of integration } \\
\text { (winter 1990) }\end{array}$ & January 1-March 15 & February $25-28$ & February 27 \\
\hline Number of grid points & $100 \times 100$ & $120 \times 100$ & $140 \times 100$ \\
\hline $\begin{array}{l}\text { Physical domain size } \\
(\mathrm{km} \times \mathrm{km} \text {, approx. })\end{array}$ & $4800 \times 4800$ & $550 \times 470$ & $110 \times 80$ \\
\hline Number of vertical levels & 20 & 30 & 46 \\
\hline $\begin{array}{l}\text { Vertical sponge:distance } \\
(\mathrm{m}) / \mathrm{nb} \text {. of levels below lid }\end{array}$ & $9000 / 5$ & $9000 / 7$ & $9000 / 10$ \\
\hline Time step (s) & 600 & 60 & 5 \\
\hline Spectral nudging & Yes & No & No \\
\hline $\begin{array}{l}\text { Spinup of sfc } \\
\text { prognostic variables }\end{array}$ & No & Yes & Yes \\
\hline Archival period (h) & 6 & 1 & 1 \\
\hline
\end{tabular}

compared to fields of the $N C E P-N C A R$ reanalyses as well as ANETZ station observations aggregated onto few CRCM 60-km gridpoints. Simulated winds at $60 \mathrm{~km}$ archived at one-hour interval are first scrutinised to detect any potential extremes over Switzerland. This step aims at identifying the moment in time at which windspeeds exceed a given threshold. Having detected high windspeed during the period of February 26-27, 1990, results of the $60-\mathrm{km}$ simulations are further downscaled to 5-, and then to $1-\mathrm{km}$ resolution. Selected results synthesising best the model performance at the meso and local scales, particularly regarding the flow fields, are compared with observations, then illustrated and commented upon. The main emphasis will be placed on the ability of the model to simulate the appropriate largescale flow, to track the surface windstorm over Switzerland, to reproduce the frontal passage on the afternoon of February 27, and to assess the associated features at finer scales. Finally, the areas of fastest simulated windspeed are compared with a survey of forest damage in southern Switzerland.

\subsection{The $60-\mathrm{km}$ simulation}

The $N C E P-N C A R$ and simulated synoptic conditions at 0000 UTC on February 27 are illustrated in Fig. 6. The $60-\mathrm{km}$ simulated mean sea-level pressure, the 1000 $500 \mathrm{hPa}$ thickness as well as the wind field at $1000 \mathrm{hPa}$ are similar to that of the reanalysis data. At mean-sea level, the Azores anticyclone is well reproduced but tends to be $1.5-2 \mathrm{hPa}$ weaker than the observed high. The model tends to simulate two distinct low centres, one over the Norwegian Sea, and the other over Sweden which can been seen on weather maps of the $D W D$ synoptic charts referred to by Schüepp et al. (1994), as well as on these of the $S M A$. It is also well located later, but its central pressure only reached $951 \mathrm{hPa}$ whereas the observed pressure fell to $948 \mathrm{hPa}$ during the same period of time. The simulated low-pressure tendencies exhibit a similar pressure drop ahead of the main cyclone between 0000 and 1200 UTC, and the simulated low-pressure centre moved in the right direction. The maximum deepening rate in a $12-\mathrm{h}$ period is located over the Gulf of Bothnia, south of Finland, and has a value of $23 \mathrm{hPa}(12 \mathrm{~h})^{-1}$ compared to a $25 \mathrm{hPa}(12 \mathrm{~h})^{-1}$ in the reanalyses. A mesoscale perturbation can be observed running southwest from the Swiss Alps to the Pyrenees from February 25-28, which is much less pronounced in the reanalyses but clearly seen in the $D W D$ as well as those of the $S M A$. This is most likely caused by the frontal cyclone crossing the Alps where the cold front structure is modified and the lee-side cyclogenesis is enhanced (Buzzi and Tibaldi 1978; Buzzi et al. 1987). The $1000-\mathrm{hPa}$ winds tend to be similar to the reanalysis data on the average, apart from some localised areas where differences of 0.5 to $1.5 \mathrm{~m} \mathrm{~s}^{-1}$ occur over the northern Atlantic, and 1 to $5 \mathrm{~m} \mathrm{~s}^{-1}$ over the continent. The simulated jet-stream at $300 \mathrm{hPa}$ is well positioned and of similar magnitude relative to the observed one. The model shows a warm bias and lower surface pressure behind the cold front late on February 26, and the thermal ridge seems to have progressed more rapidly compared to the reanalysis (Fig. 6b). The polar front thus occludes more rapidly to the west of Sweden in the simulation compared to the reanalyses. The simulated short baroclinic wave travelled faster than the observed one, the secondary depression north of Switzerland is also less well defined, so that the associated cold front reached Switzerland before the observed front on February 27 in early afternoon.

Simulated windspeed are compared to the observed ones, using ANETZ hourly averages aggregated onto the CRCM 60-km grid. The ANETZ network contains over 70 fully automatic stations, which are distributed over Swiss territory. Wind speed is compiled every 10 min; it is measured by anemometers located $10 \mathrm{~m}$ above the ground. The hourly mean is taken as the mean of the 6-hourly values. The gust is an hourly maximum value, which is taken as the maximum of six values. Even though the data is not homogenised by the $S M A$, an extensive study done by Ehinger et al. (1990) showed that winds records are considered reliable.

The observed windspeeds obtained from ANETZ have been averaged over the $60-\mathrm{km}$ CRCM grid. Over 
Table 2 List of momentum $\left(\sigma_{M}\right)$ equivalent sigma level for a reference atmosphere over flat terrain with their approximate height $\left(Z_{M}\right)$ above surface in meters. The surface level is at $\sigma=1$

\begin{tabular}{|c|c|c|c|c|c|c|}
\hline \multirow{2}{*}{$\begin{array}{l}\text { Level } \\
\text { number }\end{array}$} & \multicolumn{2}{|l|}{$60 \mathrm{~km}$} & \multicolumn{2}{|l|}{$5 \mathrm{~km}$} & \multicolumn{2}{|l|}{$1 \mathrm{~km}$} \\
\hline & $\sigma_{M}$ & $Z_{M}$ & $\sigma_{M}$ & $Z_{M}$ & $\sigma_{M}$ & $Z_{M}$ \\
\hline 46 & & & & & 0.059 & 18226 \\
\hline 45 & & & & & 0.079 & 16346 \\
\hline 44 & & & & & 0.106 & 14453 \\
\hline 43 & & & & & 0.139 & 12707 \\
\hline 42 & & & & & 0.169 & 11449 \\
\hline 41 & & & & & 0.195 & 10527 \\
\hline 40 & & & & & 0.215 & 9899 \\
\hline 39 & & & & & 0.235 & 9326 \\
\hline 38 & & & & & 0.255 & 8800 \\
\hline 37 & & & & & 0.275 & 8314 \\
\hline 36 & & & & & 0.295 & 7861 \\
\hline 35 & & & & & 0.315 & 7439 \\
\hline 34 & & & & & 0.335 & 7043 \\
\hline 33 & & & & & 0.355 & 6669 \\
\hline 32 & & & & & 0.375 & 6316 \\
\hline 31 & & & & & 0.395 & 5982 \\
\hline 30 & & & 0.057 & 18448 & 0.415 & 5664 \\
\hline 29 & & & 0.077 & 16511 & 0.435 & 5360 \\
\hline 28 & & & 0.102 & 14700 & 0.455 & 5071 \\
\hline 27 & & & 0.131 & 13089 & 0.475 & 4794 \\
\hline 26 & & & 0.163 & 11682 & 0.495 & 4528 \\
\hline 25 & & & 0.199 & 10397 & 0.515 & 4273 \\
\hline 24 & & & 0.237 & 9271 & 0.535 & 4028 \\
\hline 23 & & & 0.278 & 8244 & 0.555 & 3792 \\
\hline 22 & & & 0.321 & 7318 & 0.575 & 3564 \\
\hline 21 & & & 0.366 & 6473 & 0.595 & 3343 \\
\hline 20 & 0.052 & 19292 & 0.413 & 5695 & 0.615 & 3131 \\
\hline 19 & 0.067 & 17602 & 0.462 & 4973 & 0.635 & 2924 \\
\hline 18 & 0.105 & 14514 & 0.511 & 4324 & 0.655 & 2725 \\
\hline 17 & 0.159 & 11842 & 0.559 & 3745 & 0.675 & 2531 \\
\hline 16 & 0.226 & 9577 & 0.607 & 3215 & 0.695 & 2343 \\
\hline 15 & 0.305 & 7647 & 0.653 & 2744 & 0.715 & 2160 \\
\hline 14 & 0.392 & 6031 & 0.697 & 2325 & 0.735 & 1983 \\
\hline 13 & 0.481 & 4713 & 0.737 & 1965 & 0.755 & 1810 \\
\hline 12 & 0.568 & 3643 & 0.775 & 1641 & 0.775 & 1641 \\
\hline 11 & 0.648 & 2794 & 0.809 & 1365 & 0.795 & 1477 \\
\hline 10 & 0.718 & 2133 & 0.841 & 1115 & 0.815 & 1317 \\
\hline 9 & 0.777 & 1625 & 0.869 & 904 & 0.835 & 1161 \\
\hline 8 & 0.825 & 1239 & 0.895 & 714 & 0.855 & 1009 \\
\hline 7 & 0.864 & 941 & 0.917 & 558 & 0.875 & 860 \\
\hline 6 & 0.896 & 707 & 0.937 & 419 & 0.895 & 714 \\
\hline 5 & 0.923 & 516 & 0.953 & 310 & 0.915 & 572 \\
\hline 4 & 0.946 & 357 & 0.967 & 216 & 0.935 & 433 \\
\hline 3 & 0.965 & 229 & 0.978 & 143 & 0.955 & 296 \\
\hline 2 & 0.980 & 130 & 0.987 & 84 & 0.975 & 163 \\
\hline 1 & 0.993 & 45 & 0.995 & 32 & 0.992 & 51 \\
\hline
\end{tabular}

Swiss territory, 16 grid points were considered. The simulated wind quantity used for comparison is the hourly maximum "anemometer-level" windspeed $\left|\vec{V}_{\text {anem }}\right|$ it is computed as follows: $\left|\vec{V}_{\text {anem }}\right|=(u * / k) \ln \left(z / z_{0}\right)$, where $u *^{2}=C_{M}\left|\vec{V}_{a}\right|^{2}, u *$ is the friction velocity, $C_{M}$ is a momentum transfer coefficient, $\left|\vec{V}_{a}\right|=\left(u_{a}^{2}+v_{a}^{2}\right)^{1 / 2}$ is the lowest model-level wind speed, $z_{\mathrm{o}}$ is the roughness height for momentum, $z$ is the height of the anemometer above the surface, and $k$ is the von Karman constant. The linear correlation coefficient $\left(r_{a s}\right)$ computed for the averaged and simulated windspeed at these gridpoints from January 1 to March 15, 1990 varies from 0.48 to
0.81 , with an average of 0.72 . The highest correlations are found on the windward side and over the Alps, whereas lowest ones are found downwind of the Alps with respect to the mean atmospheric circulation; this implies a strong topographic control on the atmospheric circulation.

To illustrate the stormy winds that occurred over Switzerland, the averaged maximum hourly wind gusts, and simulated hourly maximum windspeed at grid points number 6 (Mittelland: including stations $\mathrm{La}$ Fretta, Pully, Payerne, Moléson), number 15 (Mittelland: including stations Pilatus, Luzern, Gösgen, Zürich SMA, Wändenswill, Buchs-Suhr), number 14 (Alps: including stations Jungfraujoch, Engelberg, Gütsch, Ulrichen, Grimsel Hospiz, Altdorf), and number 20 (North: including stations Tänikon, St. Gallen, Güttingen) are shown in Fig. 7. It may be noticed that the simulated month of February was quite remarkable in terms of simulated wind variability, in accordance with the observations. It is also readily obvious that faster winds are simulated on February 27, 1990, which are not straightforwardly detected using $N C E P-N C A R$ winds alone. These winds are associated with the VIVIAN windstorm and they are simulated at the proper time despite the coarse archival frequency of NCEP-NCAR data as input for the simulation with CRCM. In Switzerland, the fastest winds are found on average on the windward side and over the summits of the Alps. The simulated hourly maximum anemometer-level wind speed is almost always smaller than observed hourly wind gusts during the same period.

A careful analysis of the observed windspeed of endof-February 1990, shows that the strong hourly mean winds and the hourly gusts are often strongly positively correlated. This means that, to a certain extent, the persistence of strong winds (above $10 \mathrm{~m} \mathrm{~s}^{-1}$ for more than $15 \mathrm{~h}$ during VIVIAN, Schüepp et al. 1994) recorded during those days are modulated essentially by a huge collection of gusts blowing regularly and having a clear temporal variability. To support this, a close look at Table 3 of the Weather Bulletin issued by the $S M A$ shows that the windspeeds, which may be taken as a 10-min mean, recorded at several stations, are different to the hourly mean windspeed given by ANETZ data on February 27, 1990. For this reason, it cannot be hoped that the model will be able to reproduce this gusty nature of the wind since this involves atmospheric behaviour not simulated with the CRCM. In addition, the simulated anemometer-level hourly maximum is not found to be significantly different to the hourly mean.

\subsection{The $5-\mathrm{km}$ simulation}

To illustrate some of the features of this transitional $5-\mathrm{km}$ simulation, the simulated winds and temperatures are compared with observations and with the $60-\mathrm{km}$ run. The evolution of the cold fronts crossing Switzerland on 


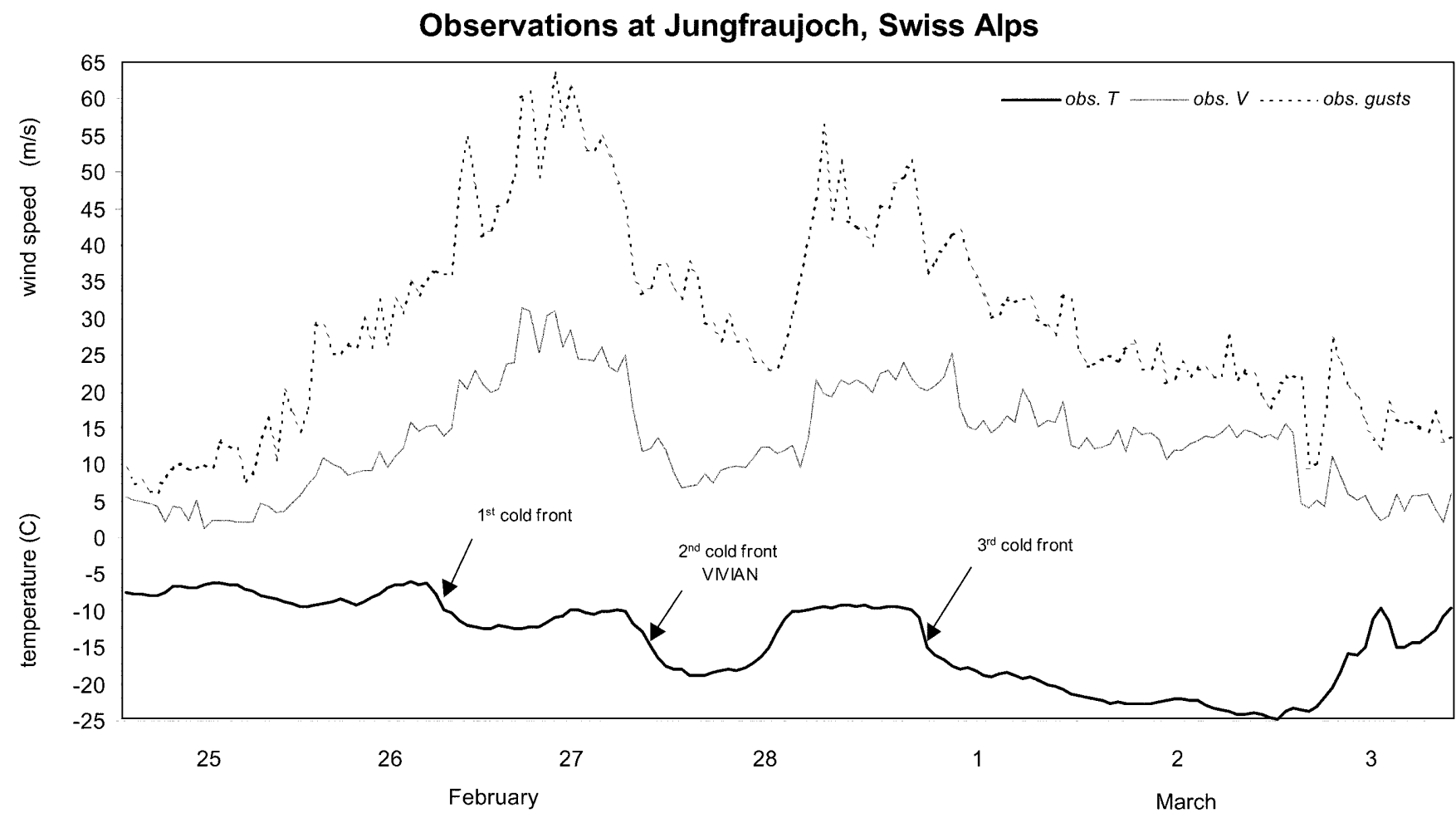

Fig. 5 Observed hourly mean windspeed (solid light grey) and maximum hourly wind gusts (dotted line) in $\mathrm{m} \mathrm{s}^{-1}$, and temperature (solid dark grey) in ${ }^{\circ} \mathrm{C}$ at Jungfraujoch station (from ANETZ)

the afternoon of February 27 is compared with the observed ones. Then, we focus briefly on a remarkable instability line as it moved with the thermal front and produced large rainfall amounts. In addition, we briefly describe an episode of gravity wave breaking that occurred during the late afternoon of February 27. Such episodes may have episodically enhanced the wind speed and gusts at the surface in the Rhône Valley.

At the beginning of this simulation, strong winds were widespread throughout the domain. The wind structure changed after a few hours where the surface topography influenced the speed and direction. While the circulation aloft is predominantly NE-ENE, the evolution of the anemometer-level wind field from early to late February 26 shows that a portion of the flow heading in the northeast direction crosses the Alps, while another portion bypasses it to the north, southward of the Jura mountains in the Mittelland. Observations indicate that warmer air was transported from SW into the Swiss Mittelland behind the first cold front on February 26 (Schüepp et al. 1994). Strong winds persisted during the morning of February 27, and the second cold front entered Switzerland from the NNW in the afternoon. Between 1200 and 1300 UTC, the cold front reached the Alps in the east and warmer air was trapped between the incoming colder air, the Alps, and the stable cold air mass aloft. By 1500 UTC, warm air was pushed into valleys across the Alps and led to this particular mesoscale flow situation which caused large damage to Swiss forests exposed to prevailing NW winds.
In order to illustrate the frontal passages, an $x$ - $t$ Hovmuëller diagram showing a cross section of the simulated $700-\mathrm{hPa}$ temperature evolution through Switzerland at $5-\mathrm{km}$ resolution from north to south over the February 26-28 period is plotted in Fig. 8. It is shown that throughout the period, the fronts are stronger over the northern part than over the southern part of Switzerland. The surface pressure in the Jungfraujoch region on the CRCM 5-km grid is roughly $700 \mathrm{hPa}$, so we can compare the evolution of the temperature (4th marked point on the arrow from left going upward) with measurements shown in Fig. 5. At 0000 UTC on February 26, temperature is about $-5^{\circ} \mathrm{C}$ and remained constant until 2000 UTC when it then dropped to $-10{ }^{\circ} \mathrm{C}$ by the end of the day. It subsequently remained steady or warmed slightly by $1{ }^{\circ} \mathrm{C}$ before undergoing a further drop of $6^{\circ} \mathrm{C}$ in the afternoon of February 27. A warm front has then raised temperatures up to $-5{ }^{\circ} \mathrm{C}$ at 1600 UTC on February 28. Although smoother than observation, the evolution of the simulated first two cold fronts matches well the behaviour of the observed ones, as well as the warm front in the Mittelland. Observations also show that the frontal passages are less well defined and weaker over eastern part of the country, such as in Ulrichen and south of the Rhône River, e.g. in Zermatt. Figure 9 shows the observed and simulated temperature evolution from February 26 to 28,1990 , at Jungfraujoch ( $3580 \mathrm{~m}$, roughly $700 \mathrm{hPa})$, Ulrichen $(1345 \mathrm{~m}$, roughly $860 \mathrm{hPa})$, and Zermatt $(1638 \mathrm{~m}$, roughly $880 \mathrm{hPa})$. Here again, the 

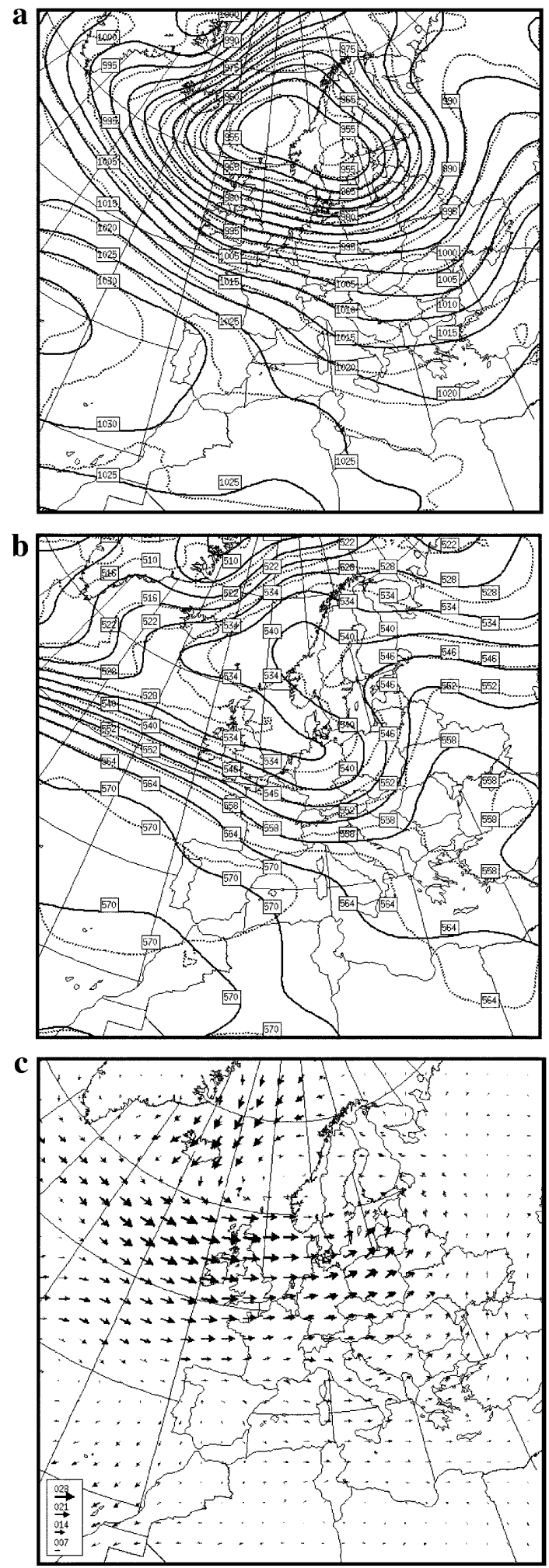

Fig. 6a-c NCEP-NCAR (solid, black) and simulated at $60 \mathrm{~km}$ (dotted, grey) mean sea-level pressure a in $\mathrm{hPa}, 1000-500 \mathrm{hPa}$ thickness b, and $1000 \mathrm{hPa}$ velocity field, $\mathbf{c}$ at $0000 \mathrm{UTC}$ on February 27, 1990 over CRCM domain $\boldsymbol{A}$. Contour interval for pressure is $5 \mathrm{hPa}$, that for thickness is $6 \mathrm{dam}$, and windspeed vectors $\left(\mathrm{m} \mathrm{s}^{-1}\right)$ shown in insert temperature evolution is strongly modulated by the variability of the orography height.

Moving along with the cold front in northern Switzerland at 1200 UTC and heading in SSW direction, a front of precipitation (more than $10 \mathrm{~mm} \mathrm{~h}^{-1}$ ) characterised by a narrow band of heavy rainfall (about $300-\mathrm{km}$ wide and 20-km long, i.e., 4-5 gridpoints) accompanied by strong upward vertical windspeed $\left(1.25-2.0 \mathrm{~m} \mathrm{~s}^{-1}\right)$, and weaker low-level horizontal windspeed is shown in Fig. 10a. At 1500 UTC, a second wave of precipitation entered northern Switzerland with intense rainfall rate (Fig. 10b). These two fronts are separated by about $80 \mathrm{~km}$, they moved slowly southwestward until about 1900 UTC, and then dissipated. The role of convection is not addressed as such because the moist convective adjustment in the CRCM is rather rudimentary and does not produce any downdrafts; thus, this scheme does not help to produce gusts at the surface. The surface wind direction and speed, precipitation rates, and the cold front evolution during this afternoon are in agreement with the observations illustrated and commented on in Schüepp et al. (1994; Fig. 5).

After the passage of the first cold front, winds turned from SW to WNW early on February 27, and maximum windspeed occurred over the alpine summits. Wind direction was perpendicular to the Alps and windspeeds exceeding $30 \mathrm{~m} \mathrm{~s}^{-1}$ were located above $1500 \mathrm{~m}$ on average on windward as well as on the lee sides. On average, during this three-day period, windspeed is positively correlated with orography height and strong vertical velocities tends to be associated with upslope and downslope winds just below the higher peaks. During the afternoon of February 27, vertical velocity of more than $1.5 \mathrm{~m} \mathrm{~s}^{-1}$ is simulated in the Bernese Alps as well as over the Alps south of the Rhône valley. In the upper troposphere, the circulation above $600 \mathrm{hPa}$ is similar on average to the $60-\mathrm{km}$ simulation in terms of their wind direction and speed.

Cross sections of the virtual potential temperature, the horizontal and vertical velocities projected across southern Switzerland along a NNW-ESE direction, are shown in Fig. $11 \mathrm{a}-\mathrm{c}$ for conditions valid at 1600 UTC on February 27. The cold front has more effect on the windward than on the leeward side of the Alps. Despite the passage of the cold front, the airflow over mountains even caused some warming on the lee side of the Jura mountains and on the lee side of the Alps in Ticino. Although the troposphere is stable on both sides of the Alps in this figure, the spacing between the isentropes on the lee side are greater than on the windward side. This means that the mid troposphere in the lee of the Alps is less stable than on the windward side. This figure shows that the horizontal wind becomes particularly strong right over the Alps, where windspeeds reach more than $30 \mathrm{~m} \mathrm{~s}^{-1}$ above the 800 -hPa level (approximately: 1500 $2000 \mathrm{~m}$ above sea level). It is also noticed that isotachs tighten over the summit of the Alps where windspeeds reach more than $30-35 \mathrm{~m} \mathrm{~s}^{-1}$. There is also a stronger 

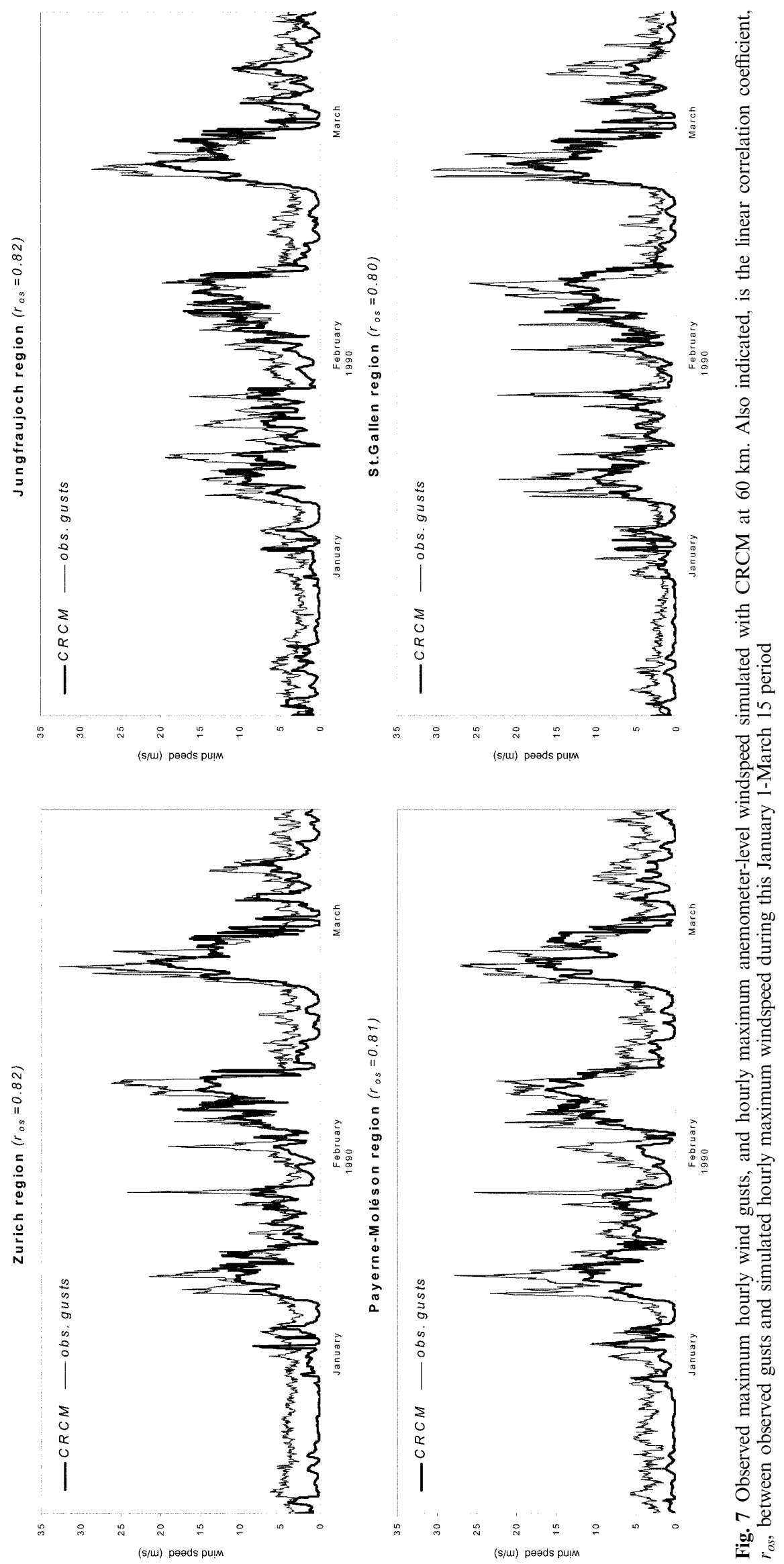
Table 3 Observed wind (speed and direction) and air temperature (10 min average) available in the weather bulletin of the Swiss Meteorological Institute at stations Sion, Jungfraujoch, Montana and Zermatt from February 26 to 28, 1990. Also hourly mean windspeeds and air temperature from ANETZ stations, NCEP-
$N C A R$ and simulated hourly mean anemometer-level windspeed and direction as well as air temperature at the nearest CRCM grid point at $60-, 5-$, and $1-\mathrm{km}$ resolution. Time is in UTC, temperature in ${ }^{\circ} \mathrm{C}$, windspeed in $\mathrm{m} \mathrm{s}^{-1}$, and direction $\left(\angle^{\circ}\right)$ in degrees where $360^{\circ}$ is north, $90^{\circ}$ is east, $180^{\circ}$ is south, and $270^{\circ}$ is west

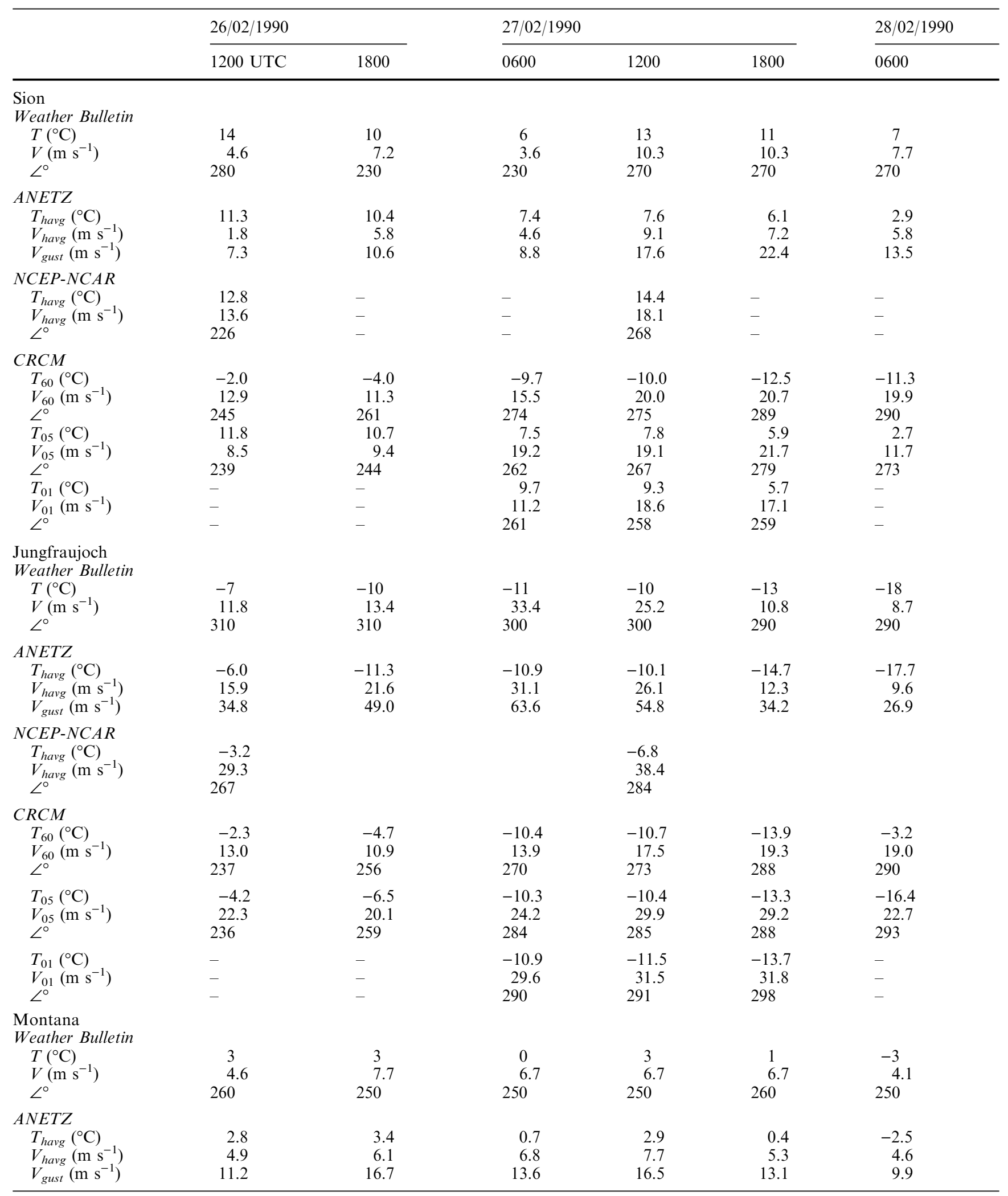


Table 3 Continued

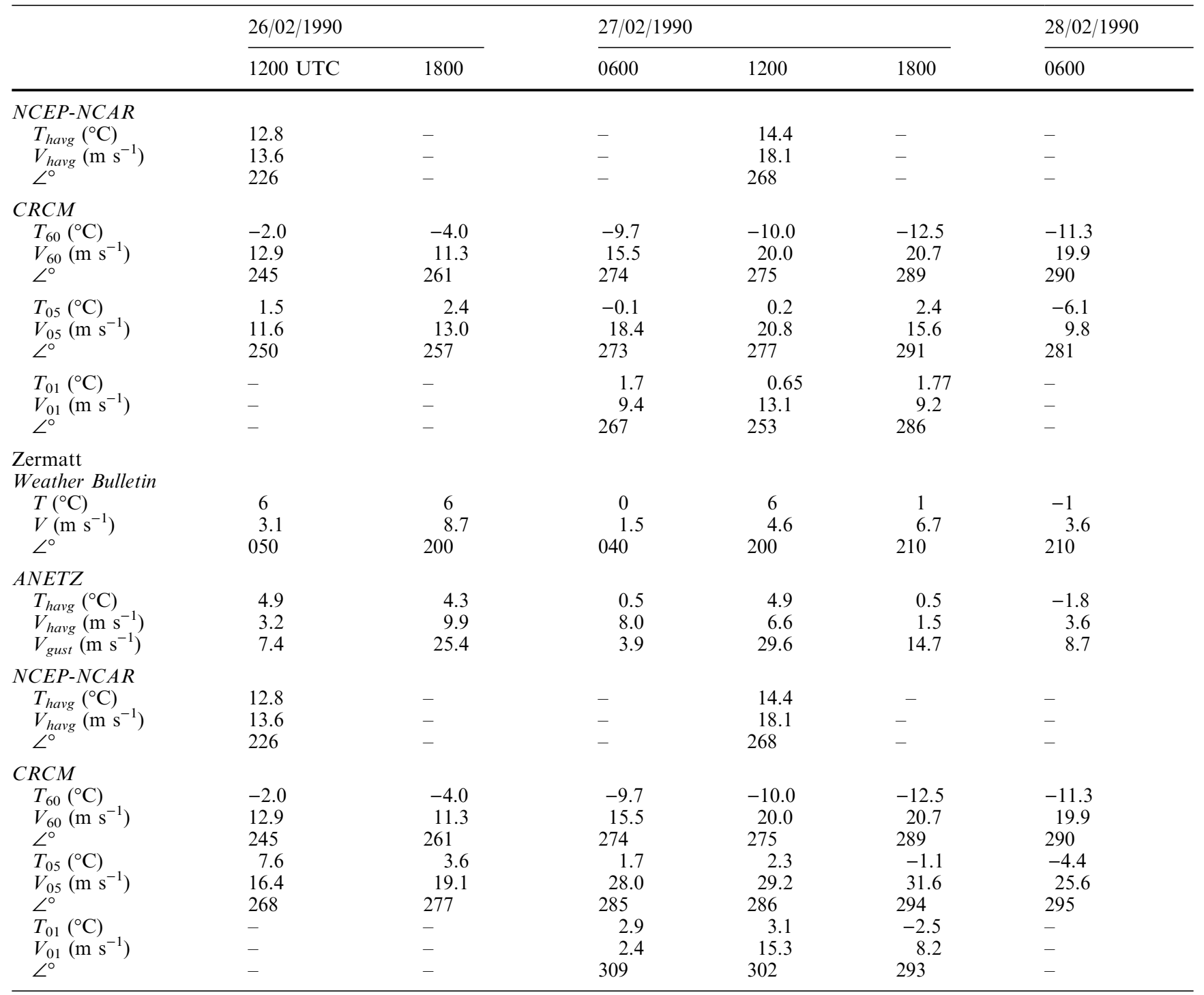

downward vertical velocity compared to the upward vertical velocity upwind of the Alps. Between 0800 and 1200 UTC the flow accelerates on both the windward and leeward slopes of the Alps above $800 \mathrm{hPa}$, but the strongest acceleration occurs in the Rhône Valley and in Ticino. The vertical velocity magnitude is maximal, upwind as well as downwind, between 0800 and 1600 UTC, where the strongest vertical velocities are found above $800 \mathrm{hPa}$ on both sides of the Alps, at more than $1.7 \mathrm{~m} \mathrm{~s}^{-1}$. During this time, a low-level jet established itself in the Swiss Mittelland between 800 and $700 \mathrm{hPa}$.

During the same day, gravity wave-breaking phenomena may have contributed to periodically enhance the windspeed at some locations in the Rhône Valley. The wave amplification and breaking is examined in Fig. 11d-f, with field differences of virtual potential temperatures, horizontal wind magnitudes, and vertical velocities between 1500 and 1600 UTC. The signature of mountain wave activity is remarkable where these three fields show an upstream tilt with height of positive and negative differences from the surface to $200 \mathrm{hPa}$ aloft to the southwest of the Jungfrau. The potential temperature shows positive differences over the Rhône Valley around $700 \mathrm{hPa}$ induced by the growth of a wave that reached its critical state between 1500 and 1600 UTC. This is followed by the formation of a shooting flow in the lee of the Jungfrau where the horizontal wind velocity differences show that windspeed has accelerated by more than $10 \mathrm{~m} \mathrm{~s}^{-1}$ in the Rhône Valley, and vertical velocity by more than $1 \mathrm{~m} \mathrm{~s}^{-1}$. Thus, the high wind speed and gusts that occurred during the February 27, 1990 storm in Switzerland is a complex three-dimensional geophysical flow problem; the study of the mountain wave problem and its application to the VIVIAN storm is beyond the scope of this study, however.

The evolution of the mean sea-level pressure field in the $5-\mathrm{km}$ run (not shown) shows that, by the end of 


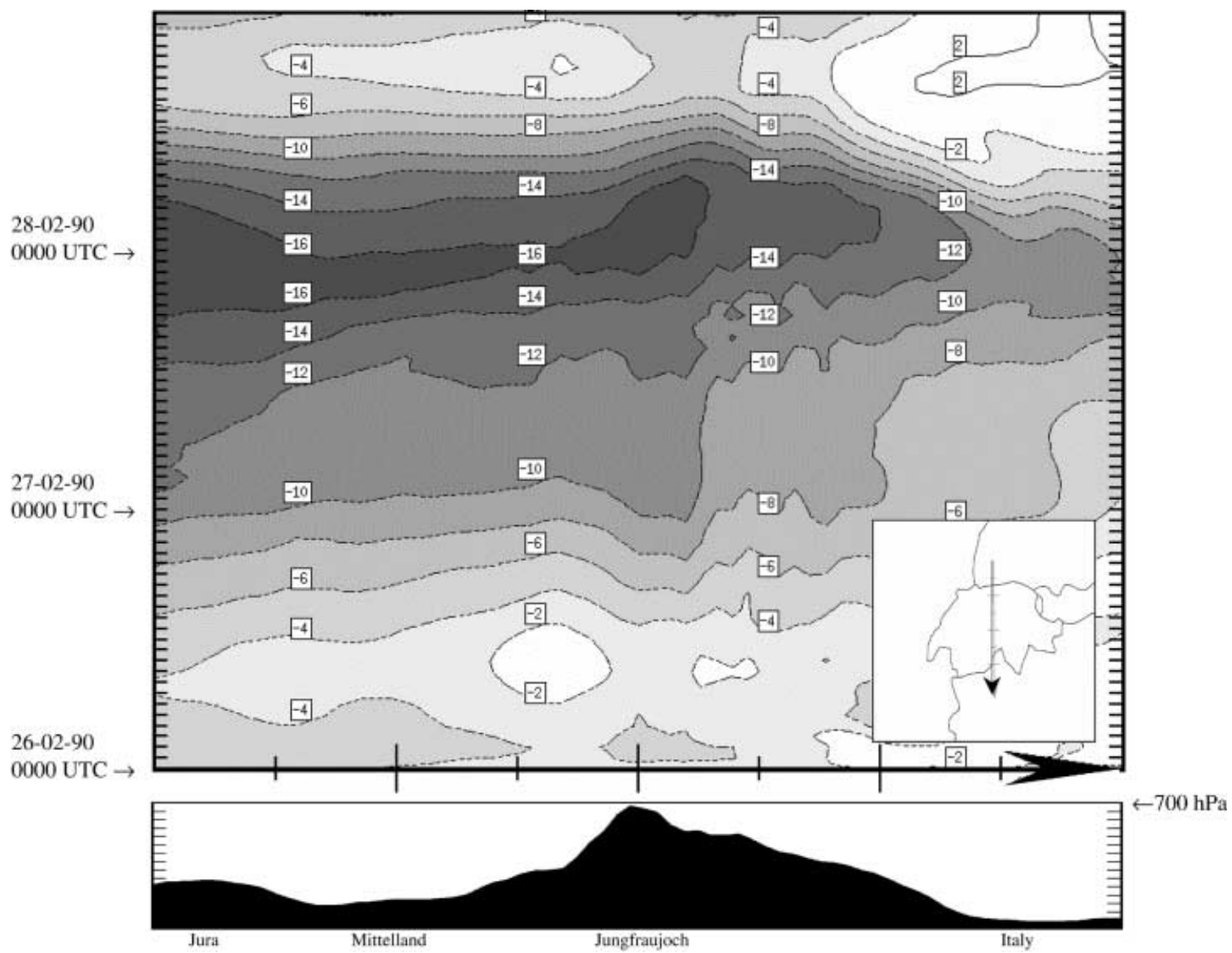

Fig. 8 Spatial and temporal cross section of $700 \mathrm{hPa}$ temperature $\left({ }^{\circ} \mathrm{C}\right)$ evolution simulated with CRCM at 5-km resolution along a northsouth baseline across Switzerland shown in insert from 0000 UTC February 26 to 0000 UTC March 1,1990 . Temperatures below $0{ }^{\circ} \mathrm{C}$ are in grey scales, contour interval is $2{ }^{\circ} \mathrm{C}$. Time (vertical axis) runs upward by one hour steps and distance (horizontal axis) runs to the right. Mountains silhouette along baseline is shown below horizontal axis, maximum height is approximately $700 \mathrm{hPa}$
February 26, a pressure dipole became established between the northern and southern parts of Swiss Alps. This dipole was reinforced during February 27, where pressure dropped to $998 \mathrm{hPa}$ downwind, compared to $1006 \mathrm{hPa}$ in the upwind at $1500 \mathrm{UTC}$. This is consistent with the results obtained at $60-\mathrm{km}$ resolution, where a mesoscale trough formed downwind of the Alps during the same period.

Comparison of windspeeds simulated at $5-\mathrm{km}$ with other simulated or observed ones is depicted in Table 3. The 5-km resolution windspeeds are quantitatively and qualitatively different from those of the $60-\mathrm{km}$ simulation. The flow at $5-\mathrm{km}$ resolution adapts its direction rapidly to the details of the orography and, as a general rule at a single gridpoint, the higher the surface elevation in either the 60 - or in the $5-\mathrm{km}$ simulation, the stronger are the winds, and vice versa. The strongest simulated winds that occurred on February 27, 1990 are reasonably well located but covering larger areas when compared to forest damage sites. There is a glimpse of the complex alpine features at $5 \mathrm{~km}$ but peaks are often still too low and valleys too high; therefore, gridpoints close to where meteorological data are collected have their elevation either below or above the "true" stations. In the present context, this bias in the surface elevation is impacting strongly on the simulated winds and temperature.

\subsection{The 1-km simulation}

In the following, we begin with the analysis of the evolution of the simulated wind field over southern Switzerland in the afternoon of February 27 in order to assess its reliability with the help of Table 3 . We then compare the windspeeds to those simulated at $60-$ and $5-\mathrm{km}$ resolution, as well as with the winds of NCEP$N C A R$, those of ANETZ station observations, and those of Weather Bulletin of the $S M A$, so as to analyse what has been gained through the downscaling procedure in terms of windspeed values and variability as well as its direction.

In the beginning of this one-day numerical experiment, strong winds were already prevalent in the domain. The synoptic flow aloft remains predominantly WNW-NNW throughout the day in accordance with 

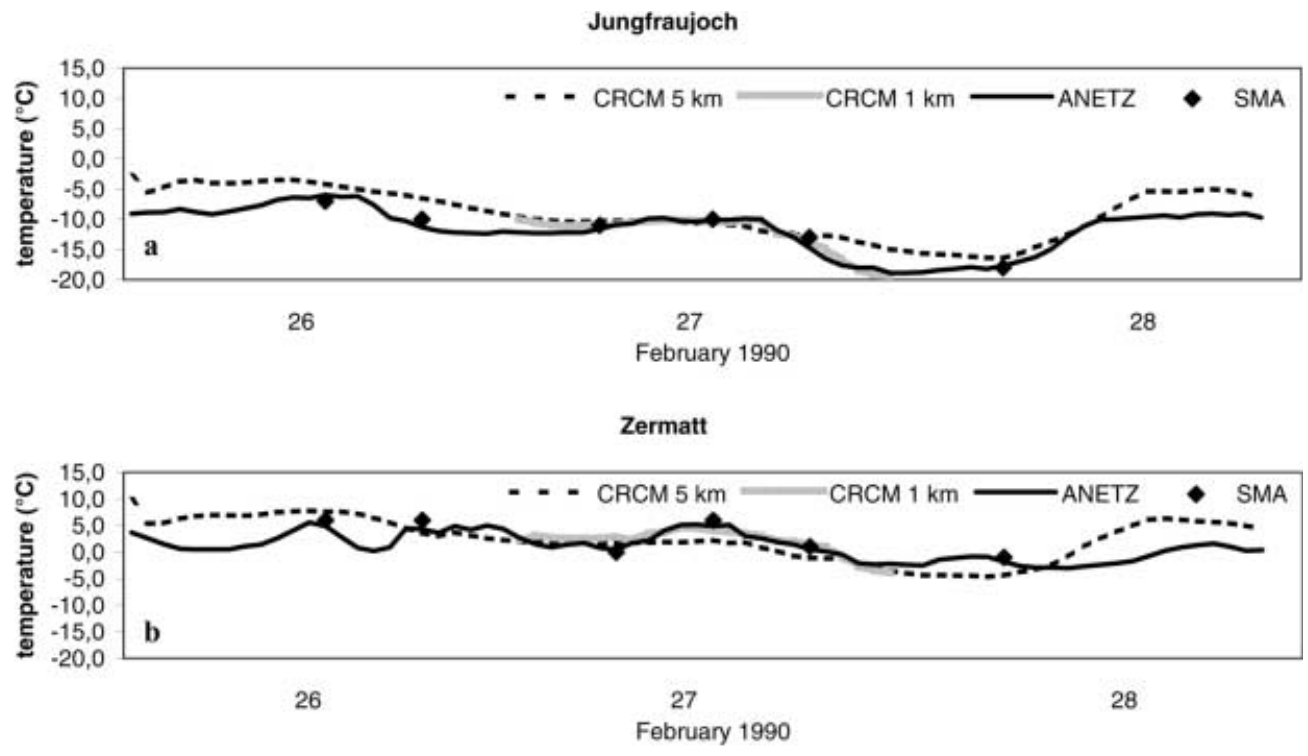

Ulrichen

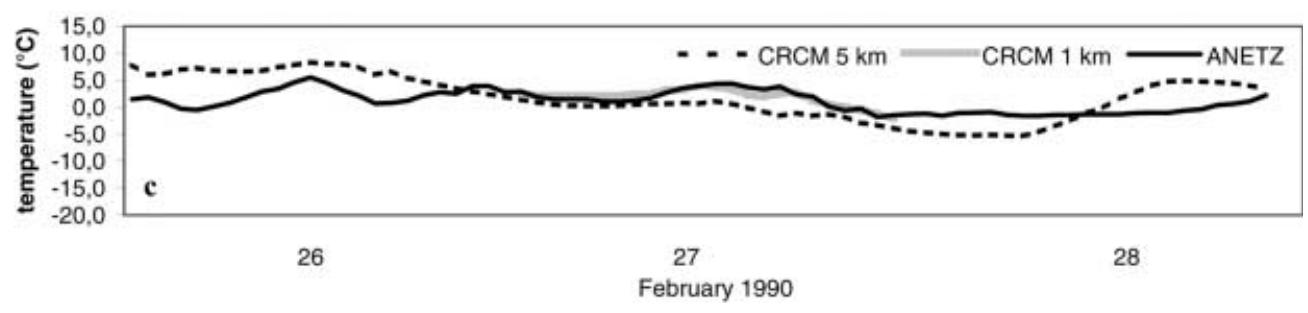

Fig. 9 Temperature evolution $\left({ }^{\circ} \mathrm{C}\right)$ at Jungfraujoch a, Zermatt $\mathbf{b}$, and Ulrichen c from February 26 to 28, 1999, according to $A N E T Z$ data (thick black line), SMA weather bulletin 10-min average temperature

(diamonds; not available for Ulrichen), and simulated with CRCM at $5-\mathrm{km}$ (dotted), and at 1-km resolution (thick grey line)

large-scale data, whereas the surface wind structure is variable and changes rapidly under the influence of highresolution topography. The winds simulated at $1-\mathrm{km}$ resolution again show the same tendency to accelerate over mountain summits where isotachs are piling up over the mountain crests and tops, and virtual potential temperature profiles show that the troposphere is stable on average throughout this day (not shown).

In order to visualise the lower-level atmospheric circulation in the Rhône valley and to understand how such severe winds could have damaged forests located on slopes, Fig. 12 shows vertical profiles of simulated wind magnitudes at six ANETZ stations. The stations, located close to areas that experienced severe wind damage are the following indicated by numbers in Fig. 14a (shown later): Jungfraujoch (1), Grimsel Hospiz (2), Visp (3), Fey (4), Interlaken (5), and Adelboden (6). The $1-\mathrm{km}$ resolution profiles, much richer in their vertical details than the 60 - and $5-\mathrm{km}$ simulation ones (not shown), indicate that a strong low-level jet established over most stations in southern Switzerland and particularly in the Valais canton. The profiles show also that the upper jet is flowing around $8000 \mathrm{~m}$ at more than $60 \mathrm{~m} \mathrm{~s}^{-1}$. At station 1,2,3, and 4, the low-level jet, reaching more than $45 \mathrm{~m} \mathrm{~s}^{-1}$, is located below $1000 \mathrm{~m}$ above the surface. There is only one vertical radiosounding provided by $S M A$ at Payerne (not lying in the $1-\mathrm{km}$ domain) in the Mittelland at 1200 UTC on February 27, 1990. Nevertheless, this vertical sounding compares well with the simulated vertical profiles of temperature and windspeed close to that region (e.g. Interlaken, Fig. 12). Surface temperature is close to $10{ }^{\circ} \mathrm{C}$ decreasing to $-50{ }^{\circ} \mathrm{C}$ at $9.7 \mathrm{~km}$ above the surface. The surface windspeed of about $20 \mathrm{Kt}\left(10.3 \mathrm{~m} \mathrm{~s}^{-1}\right)$ increases with height and reaches more than $60 \mathrm{Kt}$ $\left(30.9 \mathrm{~m} \mathrm{~s}^{-1}\right)$ in the core of the low-level jet located at about $1900 \mathrm{~m}$ above the surface. The jet-stream speed reached $150 \mathrm{Kt}\left(77.3 \mathrm{~m} \mathrm{~s}^{-1}\right)$ and is located at $9200 \mathrm{~m}$ above the surface.

The potential of this simulation for generating wind gusts at the surface is not negligible given the strong vertical shear of windspeed in the lowest layer of the atmosphere. Since wind gusts are localised and shortlived phenomena, they are considered to be subgrid scale in the CRCM. If we admit that the maximum windspeed found in the planetary boundary layer can be used as an upper limit for simulated wind gusts (e.g. Brasseur 2000), a suitable parametrisation may help to capture the extreme windspeeds observed at most of the stations listed above. 
Fig. 10a, b Precipitation, hourly mean anemometer-level wind vector, and vertical velocity at $700 \mathrm{hPa}$ simulated at 5-km with CRCM for February 27, 1990, at $\mathbf{a} 1200$ and b 1500 UTC. Precipitation is in grey tones shaded every $2 \mathrm{~mm} \mathrm{~h}^{-1}$, horizontal wind is in $\mathrm{m} \mathrm{s}^{-1}$ shown in insets, and upward vertical velocity contoured every $0.5 \mathrm{~m} \mathrm{~s}^{-1}$ in solid lines, and downward in dashed lines
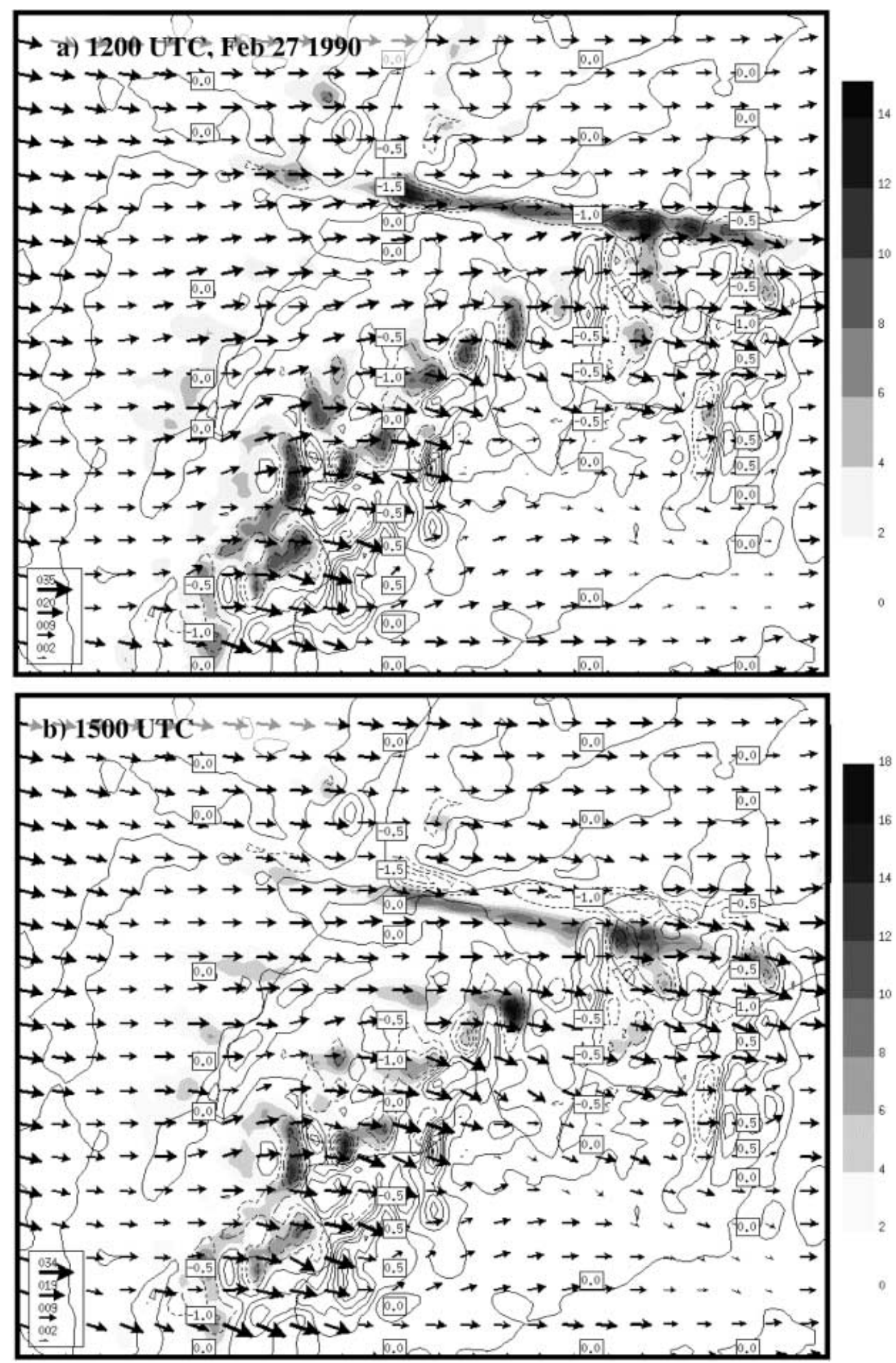

Figure 13 shows a vertical cross section of the simulated winds from roughly station 4 to station 3 at 1200 UTC during the day of February 27, 1990. The base line is located on slopes mainly NW south of the Rhône river. Close to the surface up to $700 \mathrm{hPa}$, horizontal windspeeds range from 20 to $40 \mathrm{~m} \mathrm{~s}^{-1}$. On the windward sides of this hilly terrain, the vertical velocity reaches $3 \mathrm{~m} \mathrm{~s}^{-1}$ upwind and $-2 \mathrm{~m} \mathrm{~s}^{-1}$ downwind.

Figure 14a shows the anemometer-level wind field at 1200 UTC on February 27, 1990. Its evolution from early to late February 27 shows one portion of the flow heading in the southeast direction, over the Alps, and 

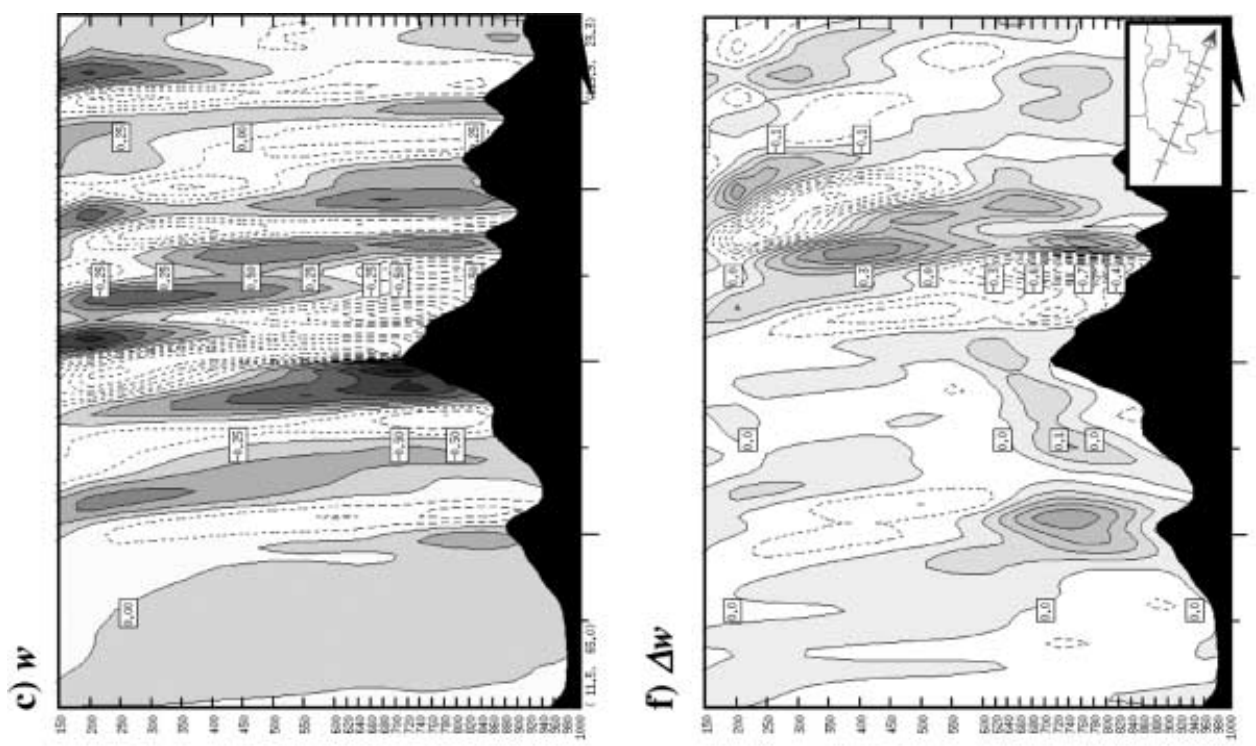

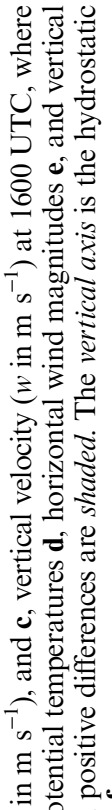
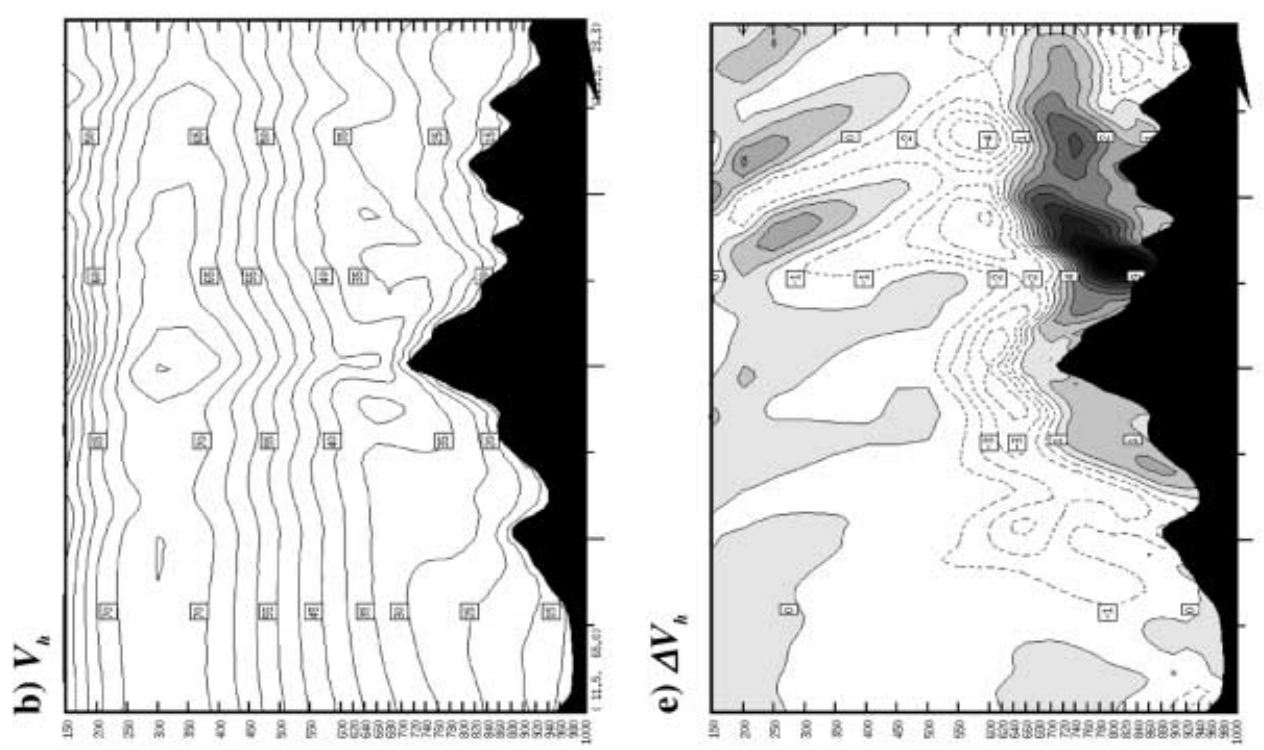

है
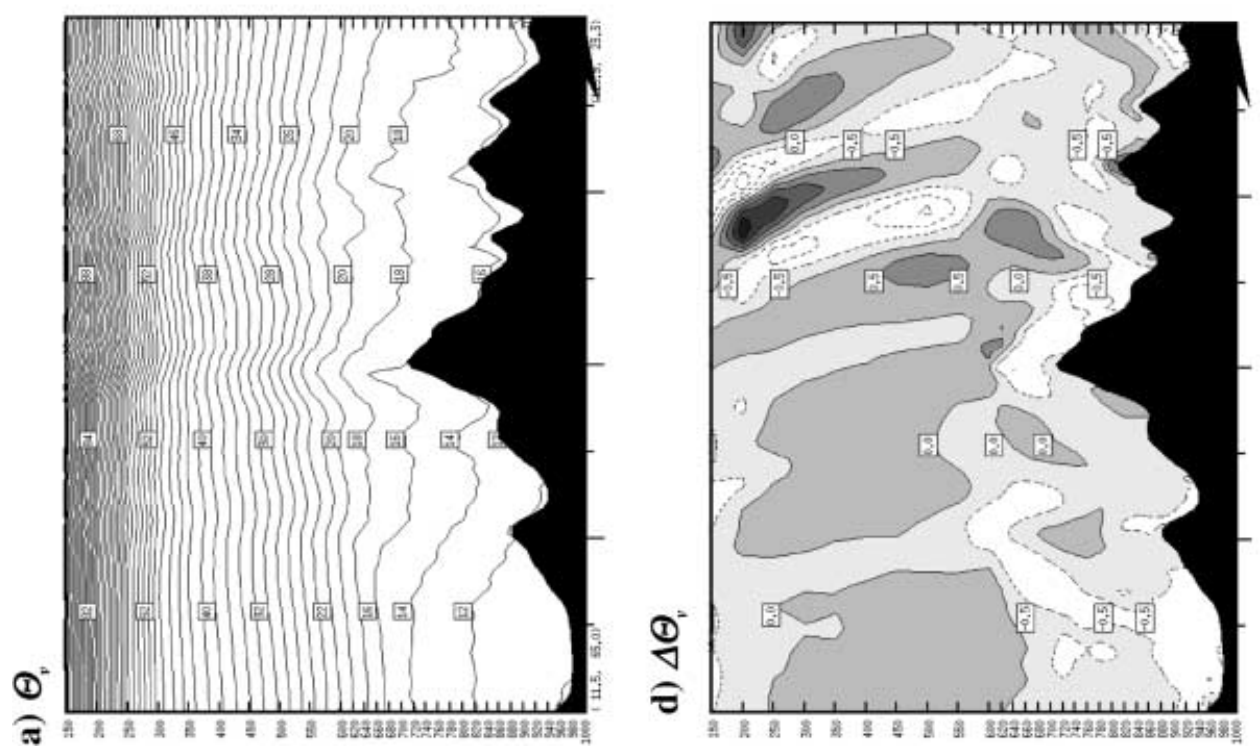

昰的

胥焉出.

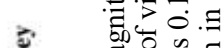

产 焉势言

范象氙

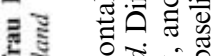

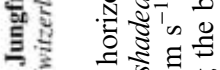

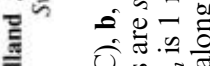

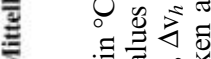

-

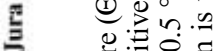

ษ

ए स्ते

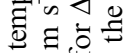

플 กำ

氙包过

․․․․

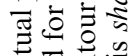

记

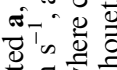

总 $\Xi \frac{\frac{9}{3}}{3}$

录泾手

क =5

훙용

范

을 층

क्ष

훈 흉

절

>.

=

엉 융 
Vertical profile of wind magnitude at Jungfraujoch, Bern (1)

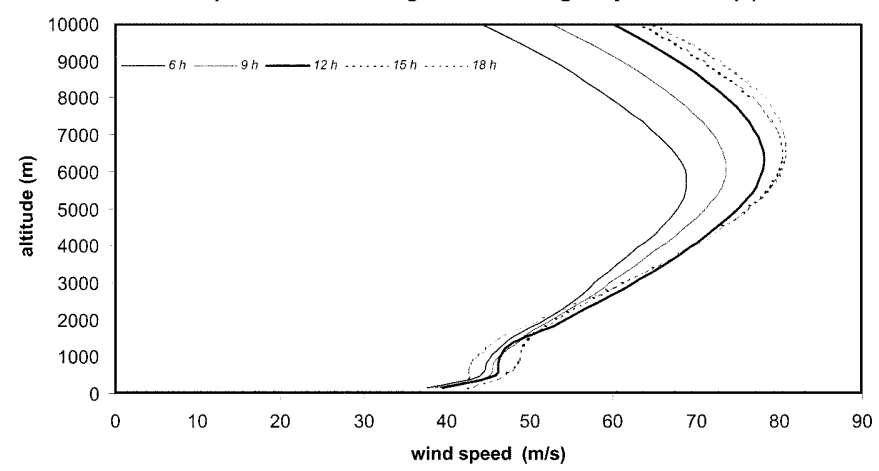

Vertical profile of wind magnitude at Visp, Valais (3)

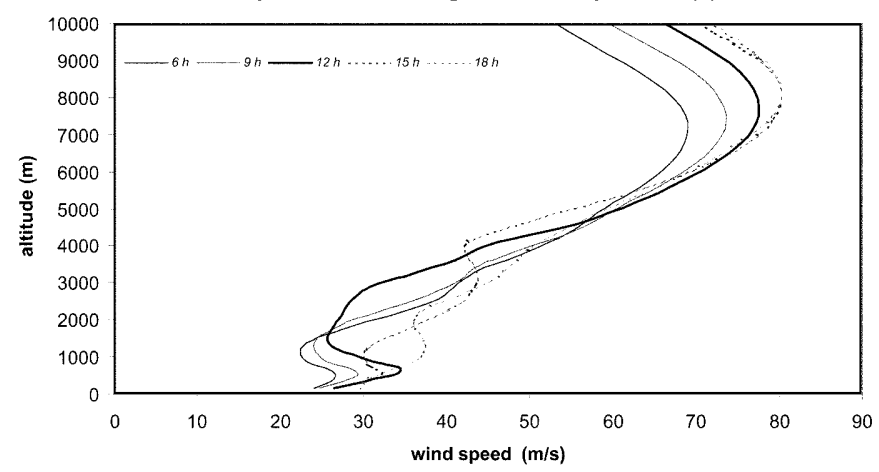

Vertical profile of wind magnitude at Interlaken, Bern (5)

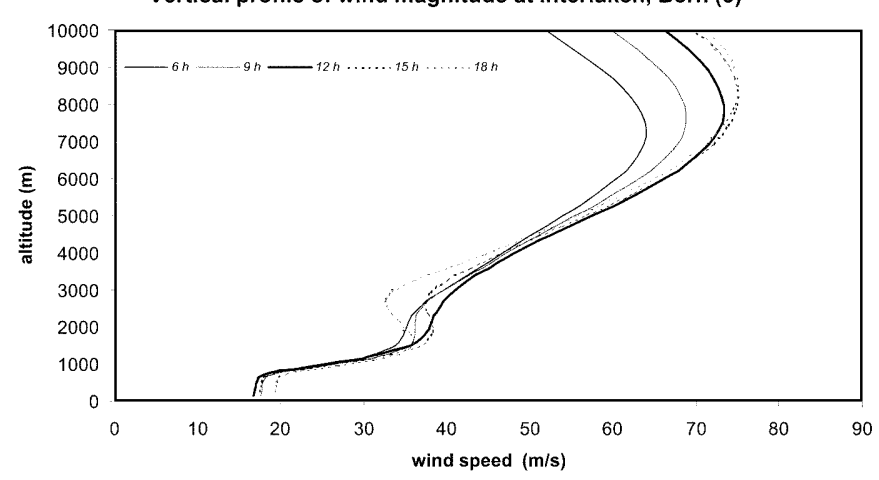

Vertical profile of wind magnitude at Grimsel Hospiz, Bern (2)
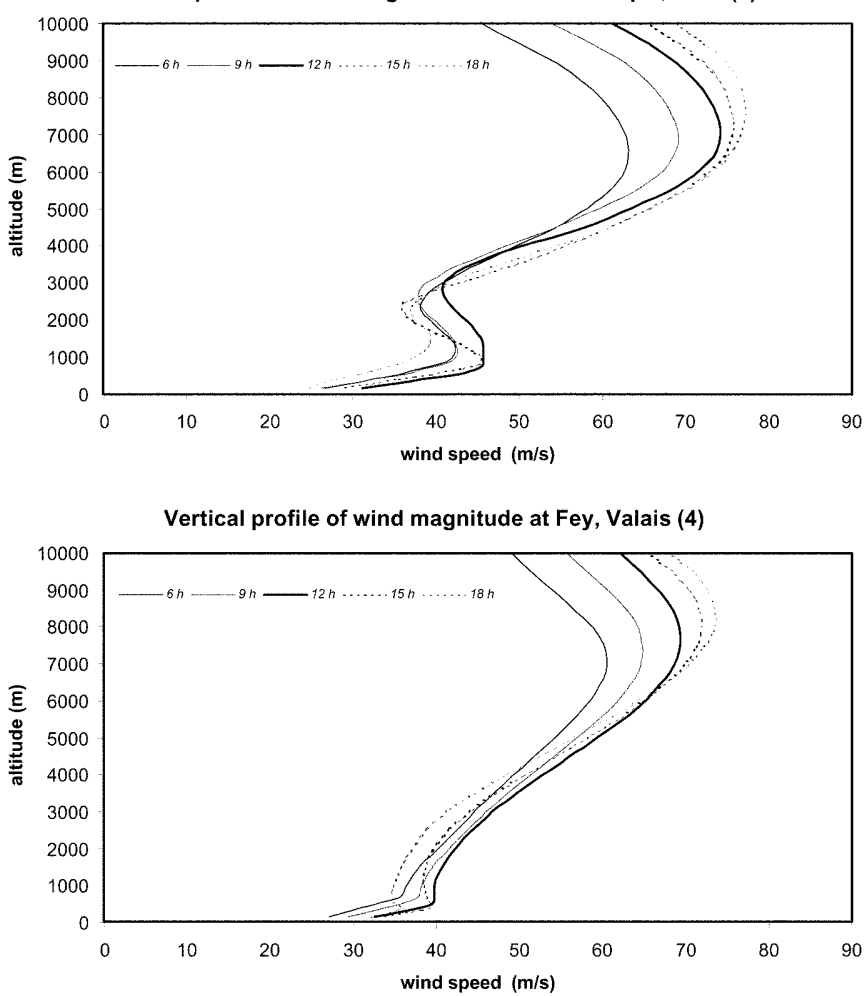

Vertical profile of wind magnitude at Adelboden, Bern (6)

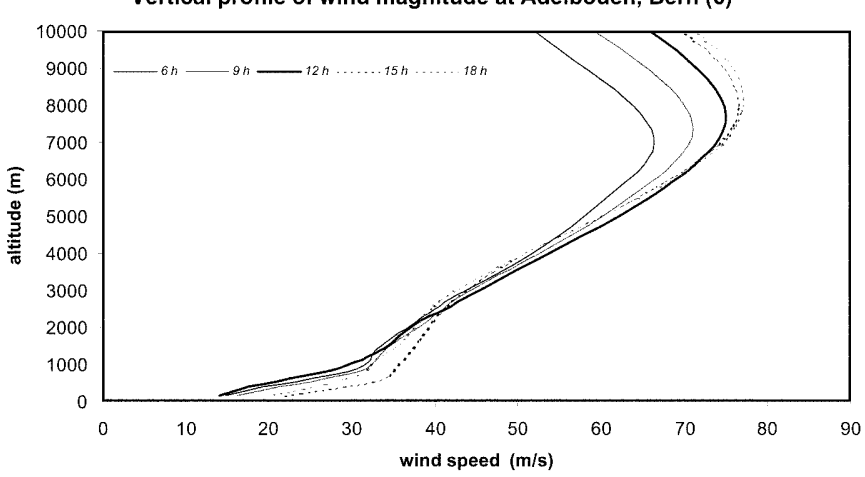

Fig. 12 Vertical profiles of simulated wind magnitude $\left(\mathrm{m} \mathrm{s}^{-1}\right)$ at 6, 9, 12, 15, and 1800 UTC with CRCM at 1-km resolution at selected stations (see Fig. 14) during February 27, 1990. Vertical axis is the approximate height (m) above local terrain

another slower portion, is channelled in to the Rhône valley in the northeast direction. The Rhône valley, in the Canton of Valais, is located at about 400 to $800 \mathrm{~m}$ above mean sea-level between the Bernese Alps to the north and the Valais Alps to the south; both chains have summits exceeding $3200 \mathrm{~m}$. The windspeed is positively correlated with surface height; fastest windspeed are found over the Bernese Alps to the north near the Jungfrau at more than $25 \mathrm{~m} \mathrm{~s}^{-1}$ on average. Strong winds are also simulated over the mountain slopes facing the northwest in the Bernese Alps as well as those in the Rhône valley. On average during this day, the fastest windspeed $\left(>20 \mathrm{~m} \mathrm{~s}^{-1}\right)$ is remarkably well correlated with observed damage areas caused by the storm and its duration (see Schüepp 1994: Fig. 2b). Forest damages due to strong winds occurred at elevations between 1000 and $1600 \mathrm{~m}$; for this range of elevation, where CRCM simulated a mean windspeed of 12 to $22 \mathrm{~m} \mathrm{~s}^{-1}$ (Beaufort 9). However, fastest windspeeds are simulated over alpine summits where there are no trees. Figure $14 \mathrm{~b}$ shows a north-south vertical cross section of horizontal wind speed over the Rhône river. Above Visp the low-level jet flowing eastward around $810 \mathrm{hPa}$ reaches $34 \mathrm{~m} \mathrm{~s}^{-1}$. The flow downwind of the Breithorn with a strong vertical shear is from WNW, while it is still flowing eastward to the northern side of the Dom massif up to $720 \mathrm{hPa}$.

Observations at four stations of the Swiss network (Montana, Sion, Zermatt, and Jungfraujoch) used for comparison with the simulated winds at the nearest CRCM gridpoint in Switzerland from February 25 to 
Fig. 13 Vertical cross section of the horizontal and vertical wind speeds along the Rhône valley from Fey (Station 4) to Visp (Station 3) at 1200 UTC simulated with the CRCM at $1-\mathrm{km}$ resolution on February 27, 1990. Vertical axis is the hydrostatic pressure in $\mathrm{hPa}$, horizontal windspeed is shaded every $5 \mathrm{~m} \mathrm{~s}^{-1}$, and vertical windspeed contoured every $0.5 \mathrm{~m} \mathrm{~s}^{-1}$, upward vertical velocity is in solid lines and downward movement is in dashed lines, and terrain silhouette shaded in black

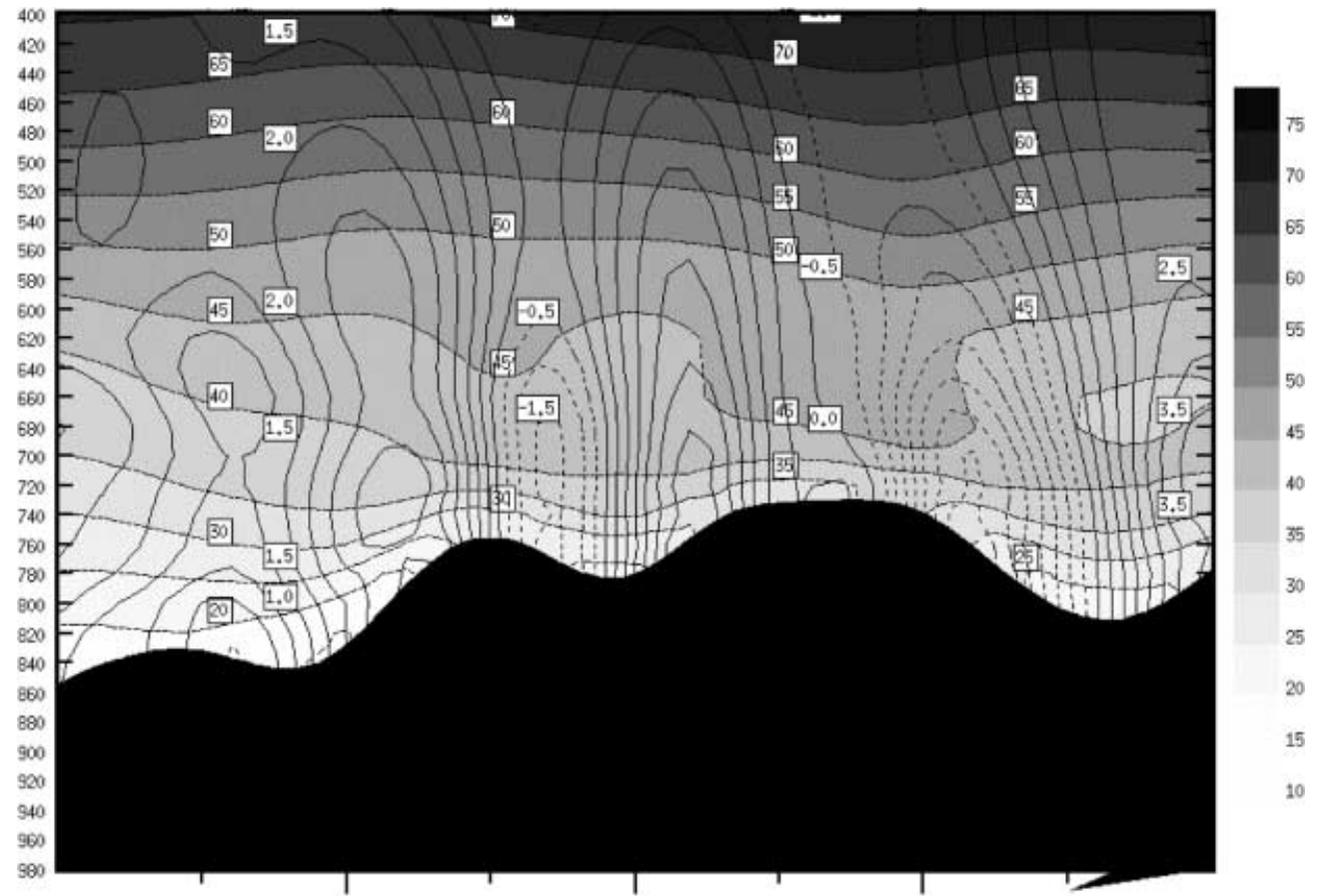

Fey

Visp
March 1, 1990 are shown in Fig. 15. Additional data is also found in Table 3 .

The spatial and temporal variability of the NCEP$N C A R$ data cannot alone help to capture the violence of the VIVIAN storm over Switzerland. The windspeed for stations 3, 4, 5 including also Zermatt and Montana, and for stations 2 and 6 originate from the same records, and archived at 0000 and 1200 UTC only. The downscaling at $60 \mathrm{~km}$ of the NCEP-NCAR data helps to enhance the space and time variability of the wind field but the simulated windspeed overestimates almost systematically the observed hourly mean windspeed, and the wind directions are systematically biased. The downscaling at $5 \mathrm{~km}$ of the $60-\mathrm{km}$ simulation increased the average windspeed values and further enhanced the variability, and finally the downscaling at $1 \mathrm{~km}$ of the 5$\mathrm{km}$ simulation increased once more the variability and enhanced the windspeed amplitude (max. - min.) over the day of February 27, 1990. For all these stations, the $1-\mathrm{km}$ resolution simulated hourly mean anemometerlevel windspeed is greater than the observed hourly mean values but smaller than the hourly gusts. The wind direction is quite realistic when compared to observation in Table 3.

It may be noticed that the surface elevation of the Jungfraujoch which, at $60-\mathrm{km}$ resolution was too low $(1243 \mathrm{~m})$, is now becoming more realistic at $1 \mathrm{~km}$ $(3300 \mathrm{~m})$. This also is the case of the anemometer-level windspeed, which increases with increasing elevation. At Sion in the Rhône Valley, the resolved surface elevation reached $1363 \mathrm{~m}$ at $60-\mathrm{km}$ resolution, $1552 \mathrm{~m}$ at $5-\mathrm{km}$ resolution, and $660 \mathrm{~m}$ at $1-\mathrm{km}$ resolution which is closer to the true elevation $(482 \mathrm{~m})$. The anemometer-level windspeed also decreases and becomes more realistic with increasing resolution. The same explanation holds for Zermatt where the resolved surface elevation reached $1363 \mathrm{~m}$ at $60-\mathrm{km}$ resolution, $2697 \mathrm{~m}$ at $5-\mathrm{km}$ resolution, and $2001 \mathrm{~m}$ at $1-\mathrm{km}$ resolution which is closer to the true elevation $(1638 \mathrm{~m})$. At Montana, the resolved surface elevation reached $1363 \mathrm{~m}$ at $60-\mathrm{km}$ resolution, $1978 \mathrm{~m}$ at $5-\mathrm{km}$ resolution, and $1603 \mathrm{~m}$ at $1-\mathrm{km}$ resolution which is closer to the true elevation $(1508 \mathrm{~m})$. These more realistic levels contribute to producing anemometer-level windspeeds which are closer to the observations.

The passage of the cold front in the afternoon of February 27, 1990, is shown to be remarkably realistic at $1-\mathrm{km}$ resolution (Fig. 9). Although the 5-km resolution model simulated generally well the time and space distribution of temperatures over Switzerland, as well as the general behaviour of the fronts, the CRCM at $1-\mathrm{km}$ resolution better captured the fronts during that day.

Finally, for the $5-\mathrm{km}$ run, the daily average of the mean mean-sea level pressure is $4-5 \mathrm{hPa}$ higher north of the Alps than south of the Alps near the Italy border, therefore the hypothesis of an orographically enhanced lee-side cyclogenesis seems to be reasonable.

\section{Discussion}

In this study, the primary goal was to devise a model setup capable of simulating the strong winds at the surface within the complex Swiss topography associated 
Fig. 14 a Simulated hourly mean anemometer-level windspeed with CRCM at $1-\mathrm{km}$ resolution for 1200 UTC. Windspeed is in $\mathrm{m} \mathrm{s}^{-1}$ with wind scale (arrows) in inset, and orography is shaded every $100 \mathrm{~m}$.

Numbers and extra names in boldface refer to some

ANETZ station locations (see text). b Vertical crosssection of horizontal wind speed along baseline (arrow pointing southward) shown in a above Visp in the Rhône Valley. Windspeed is in $\mathrm{m} \mathrm{s}^{-1}$ shaded over $30 \mathrm{~m} \mathrm{~s}^{-1}$ Vertical axis is the hydrostatic pressure in $\mathrm{hPa}$, terrain silhouette is in black

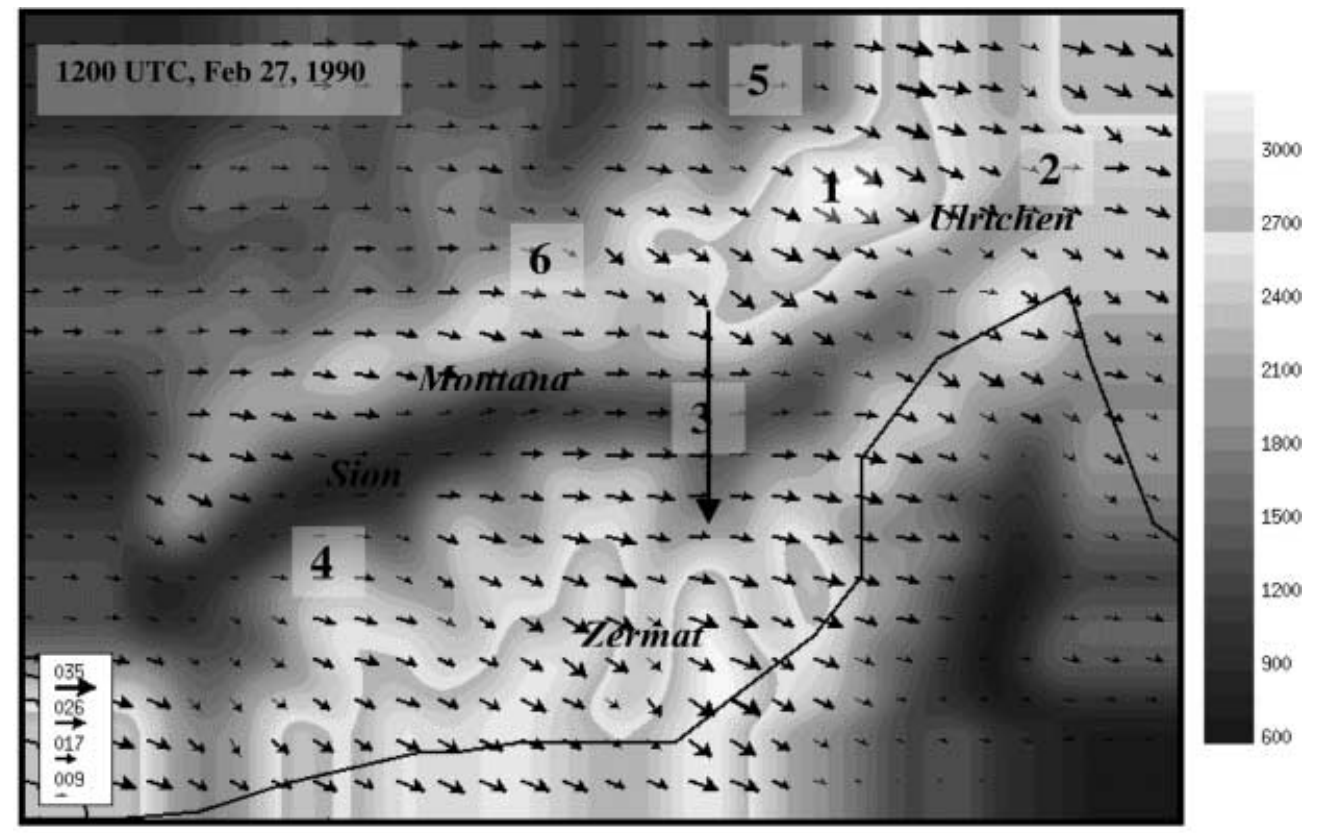

a

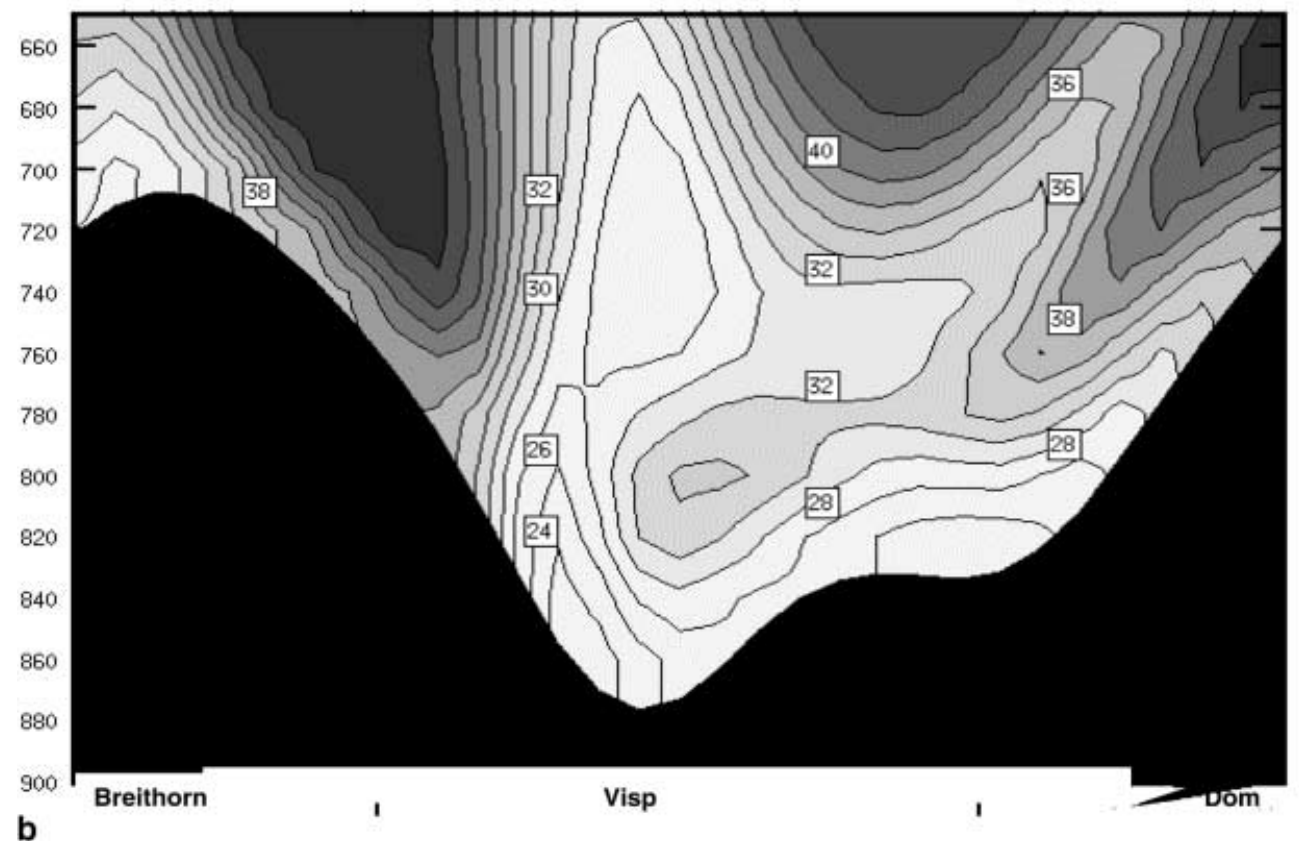

with storm VIVIAN upon downscaling NCEP-NCAR reanalyses with the CRCM. It has been pointed out in the previous section that the maximum windspeed at $1000-\mathrm{hPa}$ level were about at $15 \mathrm{~m} \mathrm{~s}^{-1}$ over a relatively large area in Switzerland. Thus, solely on the basis of the reanalysis data, the impact of windstorm VIVIAN over Switzerland cannot be projected as such, because these winds, while strong, are not extreme; smoothed in time, and furthermore, fine spatial details are not resolved.

The spatial resolution of the reanalysis data is too coarse and the 12-h archival frequency is not appropriate to infer directly any of the strong winds and wind gusts responsible for most of the damages in the Swiss valleys. We demonstrated that simulated winds at the anemometer level with the CRCM at $60 \mathrm{~km}$, computed at each time step, cumulated and archived each hour, can be used to increase the space and time variability and to accurately downtrack this specific event.

Subsequently, using model-generated outputs, an "reasonable" cascade self-nesting technique is performed to produce a 5-km simulation for February 25-28, 1990 period. We showed that, for stations whose surface elevation increased with enhanced horizontal resolution (e.g. Jungfraujoch), the simulated windspeed at the anemometer level intensified and vice versa; it did also with a more frequent update of the lateral boundary conditions 
Fig. 15a-d Observed windspeed (10 min average) given by the Swiss Meteorological Institute weather bulletin (diamonds), hourly mean and maximum wind gusts from ANETZ (respectively solid black and dotted curved), and hourly mean anemometer-level windspeed simulated with CRCM at 60-, 5-, and 1-km resolution (solid grey curves) at a Sion (482 masl), b Zermatt (1638 masl), c Montana (1508 masl), and d Jungfraujoch (3580 masl) for February 25-March 1, 1990. Units are $\left(\mathrm{m} \mathrm{s}^{-1}\right)$. Note the different vertical scales used
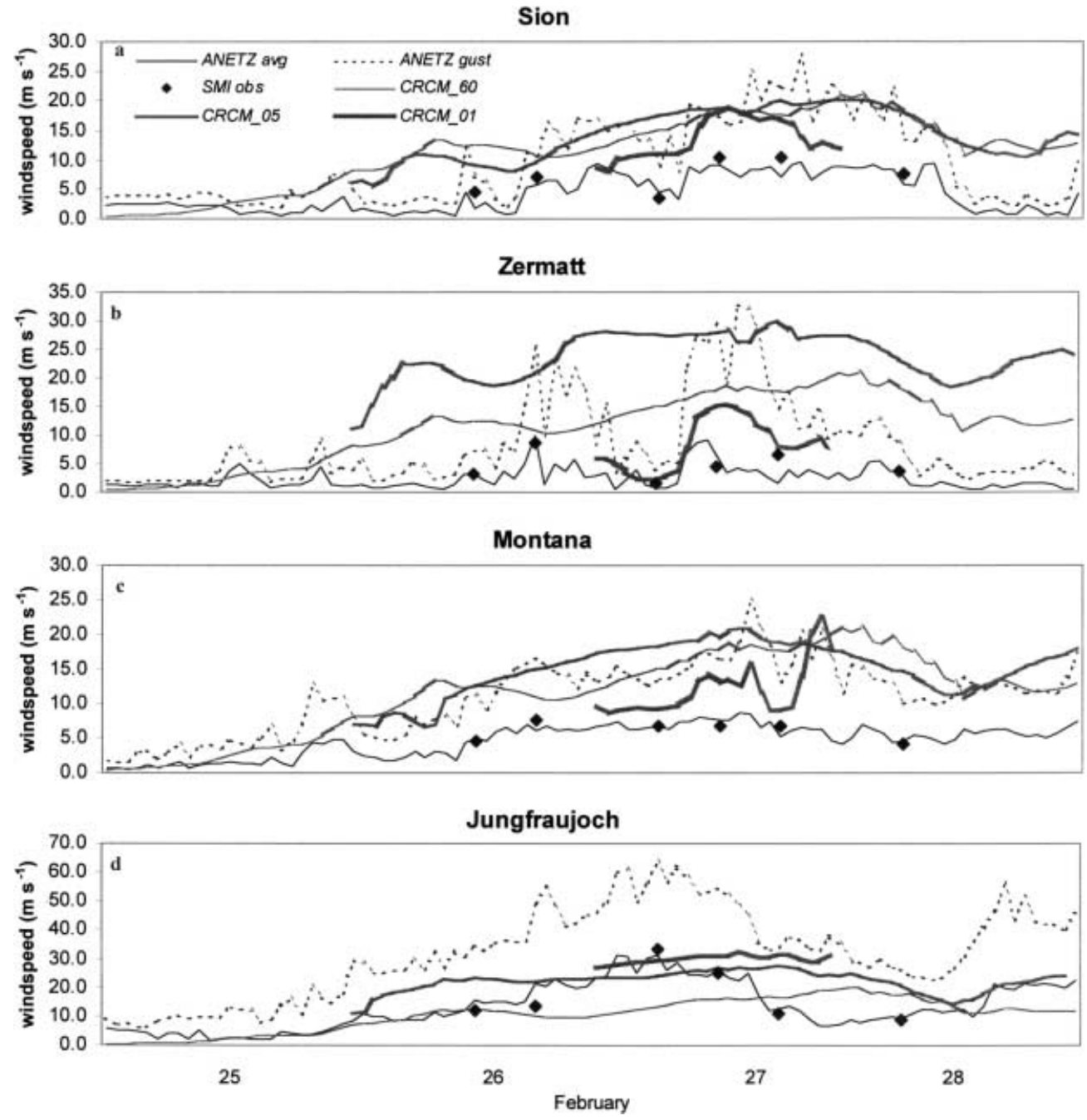

(not shown). This is also true for the windspeed variability and amplitude (i.e., difference between simulated maximum and minimum values) for most stations. For example at the Jungfrau the mean windspeed more than doubled (from 15 to $30 \mathrm{~m} \mathrm{~s}^{-1}$ ) when passing from the 60$\mathrm{km}$ resolution to the $1-\mathrm{km}$ resolution simulation for February 27, 1990, and for many stations the amplitude also doubled. This suggests that, as finer scales are reached in the horizontal with the multiple self-nesting technique, the vertical and the nesting frequency enhancement help to simulate windspeed magnitude and variability. We also showed that the frontal passages over complex mountains can be well illustrated using a Hovmuëller $x$ - $t$ diagram across Switzerland as well as with time evolution plots at a few stations.

In order to capture the precise locations of strongest winds where forest damage has been reported, resolution finer than $5 \mathrm{~km}$ is necessary in this particular case. Using the cascade self-nesting procedure we showed that simulated winds at $1-\mathrm{km}$ resolution could be realistic in terms of the area covered by the strongest winds and in terms of hourly mean windspeed for some stations. At some stations, however, the magnitude of the simulated anemometer-level hourly mean windspeed is systematically stronger or weaker than the observed hourly mean winds. This can be explained by the fact that since tropospheric windspeed generally increases with resolved height in this simulation, stations located under their true altitude exhibit lower windspeeds than observed, the reverse is true for stations located above their true altitude. Despite the success in simulating many aspects of the windstorm VIVIAN, the intensity of the windgusts observed on February 27 were not reproduced by the CRCM.

Several factors may explain the difficulties in simulating the anemometer-level mean windspeed and gusts. The first is related to problems of measurement, i.e. of how and where climatological instruments are located. Anemometer levels are located at different heights depending on the local geographical situation, which may well differ from that in the model. The measured windspeed may also be biased because of site characteristics. The measurement height may vary from the near surface to hundreds of metres (e.g. Jungfraujoch is located on a sharp summit at $100 \mathrm{~m}$ above the reference level), so that the measured windspeed may be significantly 
biased. Wind channelling may accelerate winds to produce gusts that last a few seconds to a few minutes. The second factor is attributed to the parametrisation scheme that is employed to compute surface winds in the CRCM. The model uses the Monin-Obukov similarity theory to compute the surface turbulent fluxes that modulates the first model layer winds as well as the anemometer-level wind. Furthermore, the stable boundary layer is difficult to model. The boundary layer may not be in equilibrium with its surface forcing so we cannot expect similarity relationships to perform well. Also, the simulated anemometer-level hourly maximum is taken to be the greatest of the computed windspeed within the hour, which is not a simulation of the wind gustiness as such.

While the model's horizontal and vertical resolution are enhanced, mesoscale circulations appeared gradually and low-level jets are better captured. Although the flow characteristics remains essentially the same, episodes of gravity-waves activity, which were not present at $60-\mathrm{km}$ resolution, are simulated at higher resolution. Highest windspeeds are found over the mountains both over the upwind and downwind slopes close to the summits. The windspeeds changed greatly between the $60-\mathrm{km}$ and the $5-\mathrm{km}$ simulations and less between the 5-km and the $1-\mathrm{km}$ ones, but the wind direction is strongly influenced by more complex topographical features as we progress towards higher resolution.

The nature of the stratified flow over and around the Alps can be expressed in terms of both obstacle height $(h)$, and obstacle length $(l)$, so that two Froude numbers can be defined:

$F_{h}=\frac{U_{0}}{N h} ; \quad F_{l}=\frac{U_{0}}{N l}$

where $N$ is the Brunt-Väisälä frequency, and $U_{0}$ is the mean-horizontal upwind velocity. At $1-\mathrm{km}$ resolution around the Jungfrau, taking an average value of $0.02 \mathrm{~s}^{-1}$ for $N, 30 \mathrm{~km}$ for the cross-wind width of the massif, $l$, $1500 \mathrm{~m}$ for the obstacle height, $h$, and $30 \mathrm{~m} \mathrm{~s}^{-1}$ for the mean horizontal wind velocity, $U_{0}$, the respective Froude numbers have values of $F_{h} \approx 1$ and $F_{l} \approx 0.05$. For such moderate stratification, negative buoyancy is sufficient to prevent some part of the flow from crossing the obstacle but the presence of numerous passes in the Bernese Alps, allows the flow to find a passage through to the Rhône valley. Furthermore, lee waves may have formed downstream and contributed to acceleration of the flow on upwind slopes in the Rhone valley on the other side. Generally, during this one-day simulation, the rise in the surface height accounts for the increase in windspeed. Over the Jungfrau for example, the fractional speed up ratio, $\Delta S=(\Delta V / V)_{z}$ at a given height over the hill top compared with the speed $V$ at the same absolute elevation upwind reached $20 \%$.

It is not our purpose to give a thorough analysis of the interaction of the orography with the windfield for each of the experiments described above. This issue will be addressed in a forthcoming study.

\section{Conclusions}

Our study presented the February 1990 windstorm VIVIAN simulated with the Canadian regional climate model using a multiple, self-nesting approach on three collocated grids. The model has exhibited genuine skill in reproducing many of the storm's features, although the extreme wind gusts have not been reproduced. The model has shown, however, a great consistency in reproducing wind patterns at all resolutions. The signal of windstorm VIVIAN has been detected using CRCM output at a $60-\mathrm{km}$ resolution. Simulations of the windstorm at 5- and 1-km resolution have shown some success in reproducing the locations of strongest hourly mean windspeed but have failed in reproducing the gusts.

It is intended to use the CRCM for a long-term simulation, in order to determine the frequency of occurrence of such windstorm events over western Europe and the alpine areas in an altered global climate as projected by the IPCC (1996) for the twenty first century.

We chose to integrate the CRCM at $60 \mathrm{~km}$ with 20 vertical levels because this will be its configuration for the multi-decadal simulations. We have demonstrated that this setup is adequate for the detection of the extreme wind event of February 27, 1990. Using the same model configuration, we also detected the violent winds resulting from a south Foehn that affected northern alpine forelands of Switzerland on November 7-8, 1982. Although resulting from a totally different synoptic situation when compared to the present case, the simulated flow over the Gütsch region of Central Switzerland at $60 \mathrm{~km}$ for November 7-8, 1982 showed a similar sudden increase in windspeed, so that its detection was possible (not shown).

Lately, Brasseur (2000) has demonstrated that a physically based method for estimating wind gust numerically considering turbulent eddies deflecting air parcels to the surface gave significant results. Work is now underway to devise such a parametrisation for "in-line" computation in the CRCM; this issue will be addressed in a forthcoming paper.

Acknowledgements This research was supported by the Swiss National Science Foundation under Grant 2100-049525.96. The authors would like to thank the "regional climate modelling" team at the Université du Québec à Montréal (UQAM), Canada, for their technical assistance. Finally, we would also like to thank the reviewers for their constructive comments.

\section{References}

Barry RG (1992) Mountain weather and climate, 2nd ed. Chapman and Hall, London, pp 402

Beniston M (1997) From turbulence to climate. Springer, Heidelberg Berlin New York, pp 328

Beniston M, Diaz HF, Bradley RS (1997) Climatic change at high elevation sites; a review. Clim Change 36: 233-251

Benoit R, Desgagné M, Pellerin P, Pellerin S, Chartier Y (1997) The Canadian MC2: a semi-Lagrangian, semi-implicit wide- 
band atmospheric model suited for finescale process studies and simulation. Mon Weather Rev 125: 2382-2415

Biner S, Caya D, Laprise R, Spacek, L (2000) Nesting of RCMs by imposing large scales. In: Ritchie $\mathrm{H}$ (ed) Research activities in atmospheric and oceanic modelling, WMO/TD-No. 987, Report 30, 7.3-7.4

Brasseur O (2000) Development and application of a physical approach to estimate wind gusts. Monthly Weather Review, (in press)

Buzzi A, Tibaldi S (1978) Cyclogenesis in the lee of the Alps: a case study. Q J R Meteorol Soc 104: 271-287

Buzzi A, Speranza A, Tibaldi S, Tossi E (1987) A unified theory of orographic influences upon cyclogenesis. Meteorol Atmos Phys 36: $91-107$

Caya D, Laprise R (1999) A semi-implicit semi Lagrangian regional climate model: the Canadian RCM. Mon Weather Rev 127: $341-362$

Caya D, Biner S (2000) Sensitivity study to the initial and lateral boundary conditions with the Canadian RCM. In: Ritchie H (ed) Research activities in atmospheric and oceanic modelling, WMO/TD-No. 987, Report 30, 7.5-7.6

Caya D, Laprise R, Giguère M, Bergeron G, Blanchet J-P, Stocks BJ, Boer GJ, McFarlane NA (1995) Description of the Canadian regional climate model. Water Air Soil Pol 82: 477-482

Christensen OB, Christensen JH, Machenhauer B, Botzet M (1998) Very high-resolution regional climate simulations over Scandinavia - present climate. J Clim 11: 3204-3229

Combe J (1998) Managing Swiss forest; when climate intervenes. In: Beniston M, Innes JL (eds) The impacts of climate variability on forests. Lecture notes in science. Springer, Berlin Heidelberg New York, pp 209-219

Dickinson RE, Errico RM, Giorgi F, Bates GT (1989) A regional climate model for the western United States. Clim Change 15: 383-422

Ehinger J, Hertig J-A, Alexandrou C, Berney M, Christinat M-O (1990) Analyse de l'influence de la topographie sur les conditions d'exposition des bâtiments, Klimadatentransfer-Transfert de données météorologiques. Laboratoire de système énergétiques, École Polytechnique Fédérale de Lausanne. Rap 531.109, pp 204

Flavin C (1994) Storms warnings: climate change hits the insurance industry, World Watch Mag 7: 1-21

Giorgi F, Bates GT (1989) The climatological skill of a regional model over complex terrain. Mon Weather Rev 117: 325-347

Giorgi F, Marinucci MR, Visconti G (1992) A $2 \mathrm{xCO}_{2}$ climate change scenario over Europe generated using a limited area model nested in a general circulation model. 2 Climate change scenario. J Geophys Res D9: 9710 011-10 028
Hammond JM (1990) The strong winds experienced during the late winter of $1989 / 1990$ over the United Kingdom: historical perspectives. Meteorol Mag 119: 211-219

Holenstein B (1994) Dégâts provoqués par la tempête de 1990 dans les forêts en Suisse. OFEFP, Cahier de l'environnement 218, Berne, pp 41

IPCC (1996) Climate change 1995. The second assessment. Reports of the Intergovernmental Panel on Climate Change, Cambridge University Press, Cambridge, pp 149-185

Jones RG, Murphy JM, Noguer M (1995) Simulation of climate change over Europe using a nested regional-climate model: I assessment of control climate, including sensitivity to location of lateral boundaries. Q J R Meteorol Soc 121: 1413-1449

Kalnay E, and coauthors (1996) The NCEP-NCAR 40-year Reanalysis project. Bull Am Meteorol Soc 77: 437-471

Laprise R, Caya D, Giguere M, Bergeron G, Côté H, Blanchet J-P, Boer GJ, McFarlane NA (1998) Climate and climate change in Western Canada as simulated by the Canadian regional climate model. Atmos-Ocean 36: 119-167

Laprise R, Caya D, Bergeron G, Giguère M (1997) The formulation of the André Robert MC2 (mesoscale compressible community) model. Atmos-Ocean 35: 195-220

Marinucci MR, Giorgi F, Beniston M, Wild M, Tschuck P, Ohmura A, Bernasconi A (1995) High resolution simulations of January and July climate over the Western Alpine region with a nested regional modeling system. Theor Appl Climatol 51: 119138

McCallum E, Norris WJT (1990) The storms of January and February 1990. Meteorol Mag 119: 201-210

McFarlane NA, Boer GJ, Blanchet J-P, Lazare M (1992) The Canadian climate centre second generation general circulation model and its equilibrium climate. J Clim 5: 1013-1044

Rayner NA, Horton EB, Parker DE, Folland CK, Hackett RB (1996) Version 2.2 of the global sea-ice and sea surface temperature data set, 1903-1994. Climate Research Technical Note 74, Hadley Centre Meteorological Office, Bracknell, pp 21

Rotach MW, Marinucci MR, Wild M, Tschuck P, Ohmura A, Beniston M (1997) Nested regional simulation of climate change over the Alps for the scenario of a doubled greenhouse forcing. Theor Appl Climatol 57: 209-227

Schüepp M, Schiesser HH, Huntrieser H, Scherrer HU, Schmidtke H (1994) The winterstorm "VIVIAN" of 27 February 1990: about the meteorological development, wind forces and damage situation in the forests of Switzerland. Theor Appl Climatol 49: 183-200

Zwiers FW, Kharin VV (1998) Changes in the extremes of the climate simulated by CCC GCM2 under $\mathrm{CO}_{2}$ doubling. J Clim 11: $2200-2222$ 